\title{
DE TENTOONSTELLING VAN BOEKEN, TEEKENINGEN EN ANDERE VOORWERPEN UIT DE BIBLIOTHEEK VAN HET KONINKLIJK ZOÖLOGISCH GENOOTSCHAP „NATURA ARTIS MAGISTRA", TER GELEGENHEID VAN HET IOO-JARIG BESTAAN VAN HET GENOOTSCHAP DOOR
}

JOH. ${ }^{A}$ SCHEFFER, Bibliothecaresse van het Kon. Zoöl. Gen. "Natura Artis Magistra"

Na de „Catalogus der Bibliotheek van het Kon. Zool. Gen. Natura Artis Magistra" samengesteld door G. JANSE, uitgegeven I88I en het artikel van R. T. Maitland: Ontstaan, ontwikkeling en bloei van het Kon. Zool. Gen. „Natura Artis Magistra” I888, ter gelegenheid van het 50 jarig bestaan, waarin op pag. 22 gewezen wordt, op de grootte der bibliotheek en op eenige kostbare en zeldzame werken, is over deze weinig bekende, doch belangrijke, merkwaardige en rijke bezitting van N. A. M. zelden geschreven. Hier en daar wordt in de literatuur door bezoekers van den tuin ook iets over de boekerij vermeld; iets meer staat soms in een voorrede van het werk van hen, die korteren of langeren tijd in N. A. M. gewerkt hebben.

Zoo bijv. C. G. Giebel in zijn Thesaurus Ornithologiae 1872 , op pag. VII. N. A. M. bezit een doorschoten exemplaar met eigenhandige aanteekeningen van den schrijver.

A. Ahnfeitr in: Carl von Linnés Lefnadsminnen 1877 , beschrijft wat de reiziger, die in 1870 of daaromtrent, de fraaie bibliotheek van de Amsterdamsche diergaarde binnentrad, al zoo te zien kreeg. Behalve het portret van Linnaeus in laplandsch costuum en Linnaeus' buste door DePreter bij den ingang, noemt Ahnfelt ook de rijke collectie werken en \pm 40 lithografische en fotografische afbeeldingen van LinNaEus.

In 1878 ( 100 jarige sterfdag van Linn.) en in 1935 (200 jaar geleden dat Linn. promoveerde en de Ie uitgave van zijn Systema Natura verscheen) tijdens het Internationaal Botanisch Congres te Amsterdam werden in een der zalen van N. A. M. tentoongesteld : LinnaEana in Nederland aanwezig.

Van beide tentoonstellingen is een Catalogus uitgegeven, die dus eenigszins een aanvulling zijn op de Catalogus van I88r. Uit beiden blijkt, hoe rijk N. A. M. is aan Linnaeana. Toch geven ze niet het juiste bezit aan, daar N. A. M. het boekwerk niet inzond, als een ander het reeds had afgestaan voor de tentoonstelling.

Het Genootschap kreeg en krijgt nog steeds schenkingen, die een plaats vinden in de bibliotheek en dat zijn niet alleen boeken. Zoo bevindt zich daar een kleine collectie oude, optische instrumenten waarbij de authentieke micros- 
coop van Pieter Lyonet, die indertijd geschonken werd door den Heer A. Oltmans, conservator der Conchyliën van N. A. M.

Belangrijk is ook de collectie origineele teekeningen in too jaar bijeengebracht door schenking of aankoop. In de laatste I 5 jaren werden belangrijke legaten aan de boekerij toegevoegd zooals: de biologische bibliotheek van Dr C. KerbBert in 1927; een gedeelte van de biologische bibliotheek van DR J. MetzelaAR in 1930; een gedeelte van zijn bibliotheek stond Prof. Max WEBER reeds af in 1929; de geheele biologische bibliotheek van DR J. G. DE MAN in I930; voorts schonk Prof. J. C. H. DE MEYERE bij zijn aftreden in 1936, verscheidene werken uit zijn bibliotheek.

Het was geen misplaatste trots, die het besluit deed nemen, om bij de herdenking van het 100 jarig bestaan van N.A. M. ook een tentoonstelling te organiseeren, waar behalve de historie van $N$. A. M. een gedeelte van de bovengenoemde bezittingen te zien zouden zijn. Dit gedeelte zou dan omvatten de werken over de Zoologie in NederLand. Zonder hulp uit andere bibliotheken kon een vrij volledige verzameling tentoongesteld worden.

In de bovenzaal van het hoekgebouw werd een en ander ondergebracht. Langs de wanden van de zaal waren vitrines van kleiner formaat opgesteld en in 't midden 2 rijen lange vitrines. Hier stond ook een kastje waarin herinneringen aan G. F. Westerman, N. A. M.'s eersten directeur. $Z_{i j}$ waren afgestaan door Mevrouw H. ter Meulen-MouthaAn, kleindochter van G. F. Westerman. Aan de wanden hingen, eveneens afgestaan door Mevrouw ter Meulen: een olieverfportret van G. F. Westerman door Therèse ScHWARZE en verder oorspronkelijke aquarellen, etc. van kunstenaars die werkten in N. A. M. zooals: Allebé, Mauve, Bosboom, W. VerschuUr Jr., Jacob MaRis,

de Heer A. Kerbert stond ook eenige krijtteekeningen en aquarellen af, die in het bezit waren geweest van Dr C. Kerbert o.a. werk van L. Ansingh, G. W. Dysselhof en Th. v. Duyl-Schwartze.

Een groot olieverfschilderij, voorstellende Prof. Max Weber bezig met de sectie van een leeuw in het sectiehuis van N.A. M. waarbij eenige biologen toekijken, door Louis Stracké, was afgestaan door Mevrouw Dr A. WebervaN Bosse.

De geschiedenis van het 100 jarige Genootschap lag in de eene middenrij vitrines.

Bij den ingang stond het kastje met de oude optische instrumenten, zie: Microscopen e.A. Oude Instrumenten.

Op het portaal vóór de zaal waren langs de kanten vitrines opgesteld, waarin oorspronkelijke teekeningen lagen.

Een en ander was chronologisch gerangschikt. ${ }^{1}$ ).

1) Door gebrek aan plaatsruimte was 't niet mogelijk om altijd alle aanwezige werken van een auteur neer te leggen, dan werden of de voornaamste óf die welke het beste in dit kader pasten, uitgekozen. 
Het voorbereidende werk en de inrichting der tentoonstelling is gedaan met veel hulp van Dr H. Engel, Conservator van het Zoologisch Museum, die altijd een levendige belangstelling toont voor de bibliotheek van N. A. M.. Dat deze samenwerking zeer gewaardeerd werd, daar het zoo'n goede was, moest hier eens gezegd worden.

\section{AUTEURS 1)}

P. achter Naam en jaartal beteekent: N. A. M. bezit een los portret van den auteur. (P.) achter een titel, beteekent: portret komt voor in 't genoemde werk.

Zie: „Auteurs”, „Microscopen”, „Handschriften”, „Teekeningen”, verwijst naar de desbetreffende hoofdstukken.

De reeks Zoologische werken begon met:

Eenige bewerkingen en vertalingen van oudere schrijvers, die den grondslag legden voor de populaire natuurlijke historie.

Aristoteles. $384-322$ v. Chr. P.

Aristotelis et Theophrasti historia animalium et de plantis. Lat. interpr. Th. Gazae et P. Alcyonii; recens. cura A. Cratander. Basileae I550.

Aristotelis historia de animalibus. Graec. et I.at. J. C. Scaligero interprete. Cum ejusdem commentariis. Edit. cura P. J. Manssaci. Tolosae. I6I9.

Aristoteles. Bd. III. Von der Zeugung und Entwicklung der Thiere, übersetzt und erläutert von $\operatorname{Dr} H$. Aubert und Dr Fr. Wimmer. I860.

Aristotelis' Thierkunde. Kritisch berichtigter Text mit deutscher Übersetzung, Erklärung und Index von $\mathrm{H}$. Aubert und Fr. Wimmer. Leipzig. 1868 .

Plinius. Cajus Secundus, 23-79 n. Chr.

Boecken en de Schriften van de natuyr, aert ende eygenschap aller creaturen, enz. Uit het Hoochd. overgeset. Arnhem. I6ro.

Vijf boecken van de Nature. Leste verm. druck. Amsterdam. I650.

Vijf boecken, handelende van de nature, menschen, dieren, vogelen, enz. Amsterdam. I662.

Hetzelfde werk van nieuws overgezien door Th. v. B. Amsterdam. I770.

Hetzelfde werk. Laetsten druk. Amsterdam. 1776.

Aelianus. Claudius, $\pm 220- \pm 260 \mathrm{n}$. Chr.

De natura animalium libri XVII (Graec. et Lat.) Cum animadvers.

C. Gesneri et D. W. Trilleri, cur A. Gronovio. Londini. I744.

Albertus Magnus, graaf van Bollstädt. II93-I280. P.

Dominicaner monnik, was bisschop van Regensburg, leermeester van Thomas vaN AQUiNo, schreef behalve over planten, dieren en mineralen ook over de Valkenjacht.

1) De hier volgende opgaven zijn alleen de werken die bij den desbetreffenden auteur waren tentoongesteld. Periodieken zijn (meestal) niet opgenomen. 
De animalibus libri XXVI, novissime impressi. Venetiis. I519. (de re druk verscheen 1479).

Bartholomeus Anglicus. I230-i250.

Bartholomeus d' Engelsman, wel eens verkeerd Barthol, de Glanvilla genaamd. Hij was een Franciscaner monnik.

Dat Boeck van de Proprieteyten der Dinghen (aan het einde staat) Gheprint te Haerlem. 1485 van mi Meester Jacop Bellaert gheboren van Zerixzee.

Gedrukt in 2 kolommen met gothische letter, de hoofdletters met de hand gekleurd; met II platen, d.z. ongeveer de oudste dierteekeningen. Als manuscript was 't in Italië reeds in 1283 bekend, in Engeland in 1296 . De eerste druk verscheen \pm 1470 te Bazel. Gedurende de Middeleeuwen was het $d e$ encyclopaedie voor de natuurlijke historie.

Giovio. Paolo, (Jovius Paulus,) I483-i 552.

Hij was bisschop van Nocera en schreef een werk over Visschen, dat in 1524 voor 't eerst verscheen.

De romanis piscibus libellus ad L. Borbonium. Basileae. I53r.

Rondel.et. Guillaume, I 507-r 566.

Hoogleeraar in de medicijnen te Montpellier, schreef verschillende werken over visschen o.a.

Libri de piscibus marinis, in quibus verae effigies expressae sunt, etc. Lugduni 1554 .

Histoire entière des Poissons, composée premièrement en Latin, maintenant traduit en Franç. etc. par L. JouberT. Lion. $155^{8}$.

Gesner. ConRad, $1516-1565$.

Deze beroemde $Z$ witser was hoogleeraar in 't Grieksch te Lausanne, daarna eerste stadsdokter in Zürich. Hij schreef een heele reeks natuurhistorische werken. $Z$ ijn zoologisch werk was voorn.l. een samenvatting van dat van zijn voorgangers, en het wijzen op de samenhang met de oude wetenschap, vooral met Aristoteles, doch botanisch bracht hij de indeeling der planten, die berustte op de bouw van bloem en zaad. Het derde boek van de groote Zoölogische encyclopaedie, Historia Animalium, vormt met de, uit denzelfden tijd dateerende, Histoire de la nature des Oiseaux van BeLoN, het begin van de ornithologische literatuur en illustratie. De uitstekende houtsneden door GESNER, maakte hij naar levende of doode, doch niet naar opgezette dieren. Tot in de I8e eeuw zijn ze vaak overgenomen. Meestal had hij een teekenaar en een houtsnijder die onder zịn toezicht werkten. o.a. HaNs AsPER, Johann Thomas en Lukas Schroen.

Historiae animalium libri I-IV. F,d. secnuda, auct. et emend. Francofurti a. M. 1620.- Idem liber V. Tiguri. 1587.

Icones avium omnium quae in C. GESNERI „Historia Avium” describuntur. Zurich. I 555 .

Das Vogelbuch. Darin die Art, Natur und Eigenschaft aller Vöglen ... angezeigt wirdt, etc. Zurich. 1557.

Belon. Pierre, i5i7-I564.

Deze Franschman reisde o.a. in Palestina, Egypte, Griekenland en schreef over de verschillende dieren, die hij waarnam, zoo ook over visschen. 
La nature et diversité des Poissons, avec leurs pourtraicts, réprésentez au plus près du naturel. Paris. 1555 .

In dezen tijd ontwikkelde de ichthyologie zich sterk. BeLoN met RondelEt en IPPolito S.ALviani 1514-1572 worden wel de stichters van de moderne ichthyologie genoemd. Alle drie zagen en onderzochten ze de visschen, die ze beschreven en waarvan ze getrouwe afbeeldingen maakten, doch ze gaven zich meer moeite om de juiste namen, gegeven door de oude schrijvers, te vermelden, dan om ze zelf duidelijk te beschrijiven.

Aldrovandi. Ulysse, 1522-i605.

Hij was hoogleeraar in de medicijnen te Bologna, had een botanische tuin en mooie verzamelingen op natuurhistorisch gebied. Everials GESNER had hij jaren lang teekenaars in dienst. $Z$ ijn dier-beschrijvingen zijn vol fabels en sagen. $3 \mathrm{dln}$. vogels en I dl. insecten kwamen uit vóór zijn dood, de rest later.

Opera omnia. Bononiae. I599-1668. I3 vol. Ornithologia. I 599. 3 vol.

De animalibus insectis. 1602. (1623)*

De reliquis animalibus exsanguinibus. I606. (I623)*

De priscibus et de cetis. I6I3. ( I640)*

De quadrupedibus solipedibus. I616. (I623)*

Quadrupedum onnium bisulcorum historia. I621.

De quadrupedibus digitatis viviparis et oviparis. I637.

Serpentum et draconum historia. I640.

Monstrorum historia. 1642.

Museum metallicum. I648.

Dendrolagiae natura sive arborum historia. I668.

Colonna. Fario, r567-i66o.

Purpura. Hoc est de Purpura ab animali testaceo fusa, de hoc ipso animali, aliisque rarioribus Testaceis qui busdam, etc. Romae. I6 6 .

Opuscula de purpura, Romae primum $\mathrm{A}^{\circ} \mathrm{I} 6 \mathrm{I} 6$ edita, nunc iterum luci datum opera ac studio J. D. MAJORIS, cujus novae annotatt. acced. Kiliae. 1675 .

Cluyt. Dirk Outgers, i6e eeuw.

Was apotheker te Leiden. Hij kweekte zeldzame en geneeskrachtige planten en was een groote vriend van Carolus Clusius den botanicus. CluYT werd opgedragen een plan te ontwerpen voor den kruidhof te Leiden; ook hierna bleef zijn belangstelling voor deze instelling bestaan.

Van de bijen, hare wonderlicke oorspronc, natuer, eygenschap, ende seltsame wercken, waerin gemerct werden hare wonderlicke politien en regeringe, etc. Leyden. $\mathbf{I} 597$.

Hierin een eigenhandige opdracht van den schrijver aan Prof. J. G. Merula te Leiden.

Cluyt, Outger, Einde i6e eeuw.

Zoon van Dirk Outgers. Hij maakte botanische reizen en gaf 2 jaar botanie aan de hoogeschool te Montpellier, was eenige jaren medicus te Amsterdam en werd later tot Opziener van den kruidhof te Leiden (als opvolger van zijn vader) aangesteld.

*) ( ) zijin de jaartallen van de uitgave Francofurti a. M. 1599-1668, óók in de bibliotheek van N. A. M. 
Opuscula duo singularia. I de Nuce medica etc. II. de Hemerobio, sive ephemero insecto et majali verme. Amstelodami. I634.

Jonston. JoHANnes, 1603-1675.

Studeerde op verschillende plaatsen en promoveerde te Leiden in de medicijnen. $\mathrm{Hij}$ vestigde zich in Silezië. $Z$ ijn verzamelwerk over de dieren is:

Naeuwkeurige beschrijving van de viervoetige Dieren, der vissen en bloedloze Waterdieren, der Vogelen, der Gekerfde of Kronkeldieren, Slangen en Draken, neffens haar beeldnissen. Uit het Lat. vert. door M. Grausius. Amsterdam. r660.

Hetzelfde werk met gekleurde platen.

In de I 7 eeure begon de tijd van eigen waarneming, wat ook aan de teekeningen duidelijk te zien is.

Swammerdam, Jan Jacobsz, i606-i678.

Hij bezat een apotheek „de Star" op de Oude Schans te Amsterdam en verzorgde de medicijnkisten van de zeelui, die dan op hun beurt allerlei vreemde en kostbare zaken in ruil meebrachten. Zoodoende kreeg SWAMmeridAM een groote verzameling naturaliën, die na zijn dood verkocht werd.

Catalogus van een seer wel gestoffeerde Konstkamer, inhoudende een grote menichte van allerhand uytheemsche so natuurlijcke als konstelijck uytgewzochte dingen met onvermoeden arbeit ende meer als gemeene onkosten in vijftigt jaeren tijds vergaedert deur JoHAN JACOBSZ Swammerdam, in zijn leven Apotheker. I669.

Goedaert. Johannes, i620-i668.

Was schilder te Middelburg. Hij kweekte zelf de insecten op, die hij beschreef in:

Methamorphosis naturalis, ofte historische beschrijvinghe van den oirspronk, aerd, eygenschappen ende vreemde veranderinghen der wormen, rupsen, maeden, vliegen, witjens, bijen, motten ende dierghelijcke dierkens meer; niet uyt eenighe boecken, maer alleenlijck door eygen ervarentheyd uytgevonden, beschreven, ende na de konst afgeteyckent. Tot Middelburg. 3 dln. (P.)

Volgens gegevens van $\mathrm{Dr} A$. C. OUdemans resp. uitgegeven 1660, I664 en I Jan. I669. Latijnsche Ed. 3 dln. resp. I628, I667, I67 I met gekl. pl. (P.)

Rumpf. Georg Everhard, (G. E. Rumphius) i627-i702 P.

d'Amboinsche Rariteitkamer, behelzende eene Beschrijving van allerhande zoo weeke als harde Schaalvisschen, etc. 't Amsterdam gedrukt bij François Halma. i 705. (P.)

Van deze re ed. bezit N. A. M. een unique exemplaar, dat door M. S. Merian met de hand is gekleurd. Het is afkomstig van de auctie VosmaER in I80I en wordt in de Catalogus daarvan genoemd op pag. 10, no. 137, met de bijvoeging: „dit exempl. uit het kabinet van L. VINCENT afkomstig, heeft nauwelijks weerga". Op het schutblad van het foliowerk zelf staat geschreven en onderteekend door A. VosmaER: „Dit uit- 
muntend en mogelijk unique werk, door M. S. MERIAN allerheerlijkst afgezet, uit de Bibliotheek van den $H$. W. geb. Jonkheer $P$. Bout, en bij verkoop der zelve voor f 240 : - : - weer ingekogt op den 12 April 1779, is door de Erfgenaamen, namelijk Mevrouw van Hogrndorp, geb. Bout, en den Heere Bout, Heer van Lieshout etc. etc. aan mij vereert, in erkentenis van geringe diensten voor het maaken der Catalogus van het beroemde Kabinet der Nat. Historie van L. VINCENT, door eerstgen. Heer Bout nagelaaten."

Ie heeren G. F. Rouffaer en W. C. Muller hebben voor hun „Eerste proeve van een Kumphius-Bibliographie" in 't Rumphius Gedenckboek 1702-1902 er niet aan gedacht de bibliotheek van N. A. M. te raadplegen daar bovengenoemd exempl. v. d. Amb. Rar.k. wel genoemd wordt in noot I pag. 109 (35) doch het hun niet bekend is waar 't gebleven was. Evenzoo noemen ze uit de Bibl. d. K. Leop. D. Ak. d. Naturforscher Halle, wat ook is in N. A. M.:

Amboinische Raritäten-Kammer oder Abhandl. von den Steinschaal. Thieren, welche man Schnecken und Muscheln nennt. Aus d. Holl. übers. v. P. L. Stantius Muller u. mit Zusätzen v. J. H. Chemnitz. Wien, 1766.

Zoo ook: J. H. Chemnitz. Kleine Beyträge zur Testaceotheologie oder zur Erkäntnis Gottes aus den Conchylien in einigen Sendschreiben herausgegeben. Frankfurt-Leipzig. 1760 (waarin op pag. 74: ,die erste, beste und rareste Ausgabe van 1705” genoemd wordt en de afbeeldingen door M. S. MERIAN geroemd worden).

d'Amboinsche Rariteitkamer. Nieuwe titeluitgave van den herdruk van I740. t'Amsterdam. Bij Jan Roman DE Jonge. Boekverkoper. I74I. (op titelblad).

Van deze uitgave I exempl. met titelprent waaronder, op één regel : t'Amsterdam. Gedrukt bij Françors Halma. Boekverkoper. 1705. en I exempl. waar dit bedekt is met een strookje waarop: 't Amsterdam. Gedrukt bij JAN Roman dE JoNGE. Boekverkoper. 1740.

Een compleet stel platen + titelplaat, met de hand gekleurd. Allen het spiegelbeeld van de uitgaven 1705 en 1740.

De nummers en letters die naar de tekst verwijzen ontbreken en zijn tot en met pl. 49 bijgeschreven en de moet, ontstaan door den druk van de kopergravure, ontbreekt, zoodat bijv. pl. I, de fig. A en B geheel volledig toont.

Henschel. Ang, Gnil, Ed, Th,

Clavis Rumphiana botan. et zoolog. Acced. vita G. E. Rumphir, Plinii indici, specimenque, mater. med. Amboinensis. Vratislaviae. 1833.

RumphiUs Gedenkboek, I702-I9O2.

uitgegeven door het Koloniaal Museum te Haarlem.

Valentijn, François, I656-i727.

Oud en Nieuw Oost Indiën, vervattende een nauwkeurige en uitvoerige verhandelinge van Nederlands Mogentheyd in die Gewesten, etc. Amsterdam. I724-I 726. (P.)

Verhandeling der Zee-horenkens en Zee-gewassen in en omtrent Amboina. Tot vervolg van de Amboinsche Rariteitkamer, door G. E. Rumphius. Amsterdam. I754. (P.) 
Leeuwenhoek, Antony van, 1632-i723. P. is Verkolje's mezzotint.

N.A.M. bezit verscheidene werken van v. Leeuwenhoek, zoowel latijnsche als hollandsche. Daar de opgave hiervan ingewikkeld is, verwijs ik naar: Antony van Leeuwenhoek and his "Little Animals”. by Clifford DoBELL. 1932. pag. 392 waar alle publicaties van v. L. vermeld staan.

Hollandsche uitgave:

I, 2, 4, 5, 5b, 6, 6a, 7, 7a, 8, 8a, 9, 9a, Iob, I2a, I3, I4, I5, 16, I8, 19.

Latijnsche uitgave:

$24 \mathrm{c}, 25 \mathrm{c}, 26 \mathrm{a}, 27,28,29$.

Van I, bezit N.A.M. de uitg. door D. v. Gaesbeeck. I684 maar met brieven 32, 33 en 39 ; in deze volgorde en ook de 2e editie, uitg. H. v. Kromvelt 1694, niet genoemd bij Dobell, wel in Nature No. 3288, pag. 680, maar met brieven $32,33,37$.

LEEUWENHOEK is verschillende keeren herdacht o.a. bij zijn I00-jarigen sterfdag I823,

HaAstert. IsaAC VAN, I753--1834. (zie „Handschriften”).

Anth. van Leeuwenhoek vereerend herdacht in een korte levensschets en lofdicht etc. 26 Aug. I823.

volgens DoBelu.: Extremely rare. No copy found in England. Unimportant.

In 1843 en I844 kwamen te Leiden 3 proefschriften uit over A. v. LEEUWENHOEK onder Prof. A. v. D. HoEven, waarvan het Ie een vrij uitvoerige levensbeschrijving is.

Halbertsma. Hiddo,

De Leeuwenhoeckii meritis in quasdam partes anatomiae microscopicae. Daventriae. 1843 .

volgens DoBELL: Important. Now very rare.

Fleck. F. Le Sueur,

titel gelijk voorgaande. Lugduni Batavorum. I 843 .

Charante. N. H. van,

titel gelijk voorgaande. Lugduni Batavorum. I843.

In 1875 werd v. Leeuwenhoek herdacht als ontdekker der Infusoria (200 jr. geleden). Haaxman, P. J. (Apotheker te Rotterdam.)

Antony van Leeuwenhoek. De ontdekker der Infusorien. 1655-I875.

Dit is de eerste biografie van waarde en volgens DoBeLI.: Fundamentally important, and now very rare.

Engelmann. Th. W.

Onderzoekingen over ontwikkeling en voortplanting van Infusoria, bij de feestelijke herdenking v. d. ontdekking der mikroskopische wezens etc. Sept. 1875. (Onderzoekingen physiol. lab. Utrecht. reeks III. deel III afl. 2).

Doвfl.t, noemt dit niet. 
Pijzel, E. D.

Antony van Leeuwenhoek. I875 (Gids Jrg. 39).

HaRTing. P.

Gedenkboek v. h. den 8en Sept. 1875 gevierde 200-jarig herinneringsfeest der ontdekking van de mikroskopische wezens door Ant. v. Leeuwenhoek. 1876 .

Te Delft werd 8 Sept. 1875 een tentoonstelling gehouden, hiervan bezit N. A. M. :

Lijst der tentoongestelde voorwerpen.

Voorts vele publicaties in verschillende dag- en weekbladen en andere Seriewerken bijv. in JAARBOEKJE N. A. M. 1869. P. H. WitKaMP. Vier en twintig voorgangers.

SWAMmERDAM. JAN, I637-I680.

Historia insectorum generalis, ofte algemeene verhandeling van de bloedlooze dierkens, etc. Utrecht. 1669.

Histoire générale des Insectes où l'on expose clairement la manière lente et presqu'insensible de l'accroissement de leurs membres, etc. Utrecht. r682.

Bijbel der Natuure of Historie des Insecten, met een voorrede, waarin het leven van den auteur ...... door H. BoerhaAve. - Bibiia Naturae,

Sive Historia Insectorium. Lat. vers. adscrips. H. D. Gaubius. (Belg.Lat.) Leyden. 1737.

Levensberichten, etc. over Jan SWammerdam:

Th. G. van Lidth de Jeude. Oratio de Jo Swammerdamio. Trajecti ad Rhenum. 1820.

Herdenking van Jan Swammerdam's 200-jarigen sterfdag i7 Febr. I880. (Uitg. Gen. tot bevord. van Nat. Genees- en Heelkunde).

Herdenking 300-jar. geboortedag met artikelen o.a. van: A. SchierbeEk. J. Swammerdam I637-1680. 1937. H. EngEL. J. Swammerdam, 's werels grootste entomoloog. 1937 .

Meria(e)n Maria Sybilla, i647-i7i7.

Der Rupsen begin, voedzel en wonderbaare verandering etc. $t^{\prime}$ Amsterdam, z. j. (waarschijnlijk I683-1717). 3 dln. in I bd.

Het $3 e$ deel is: „In Print gebracht, en in 't licht gegeven door haar Jongste Dochter

* Dorothea Maria Henrice." Van dit deel bezit N. A. M. de oorspronkelijke waterverfteekeningen. Alle 3 deelen, vooral de eerste $2 \mathrm{dln}$., heel mooi met de hand gekleurd.

Over de voortteeling en wonderbaerlijke veranderingen der Surinaamsche Insecten ...... Alles in Amerika door den zelve M. S. Meriaen naar het leeven en leevensgrootte geschildert, en nu in 't Koper overgebragt. t'Amsterdam. I719.

Dit werk is met handgekleurde platen, een mooi exempl.

* volgens andere opgaven: Maria Dorothea Henrica. 
Hetzelfde werk. 't Amsterdam 1730 (ongekl. pl.) De Europische Insecten naauwkeurig onderzogt, na 't leven geschildert, en in print gebragt door Maria Sibilla Merian. Tot Amsterdam. i73o.

Zie „Teekeningen'.

Blankaart. Stefanus, 1650-izo2.

Ook hij kweekte evenals GoEDAERT en MERIAN, zelf de insecten, die hij beschreef en teekende. Dit blijkt uit de toevoeging: „Door eigen ondervindinge bijeengebragt”, op 't titelblad van:

Schouburg der Rupsen, Wormen, Ma'den en Vliegende Dierkens daer uit voortkomende, etc. Amsterdam I 886.

Collectanea medico-physica oft Hollands jaer. Register der genees- en natuurkundige Aanmerkingen van gantsch Europa. I680-I688.

De volgende serie boekwerken gaven een overzicht van de reizen der Hollanders in de Ibe en I7e eeuw.

Linschoten. Jan Huyghen van, \pm I563-i6ir.

Itinerarium ofte Schipvaert naar Oost- ofte Portugaels Indien. Van nieuws ghecorrigeerd ende verbeterd. Amsterdam. 1644. - Reys-geschrift van de Navigatien der Portugaleysers in Orienten. Ald. 1644. - Beschrijving van de gantsche Custe van Guinea, Manicongo, etc. Ald. I644. (P.)

De se druk is van 1590 .

DAPPER.

Asia of naukeurige Beschrijving van het rijk des Grooten Mogols en een groot gedeelte van Indiën. Amsterdam. I672.

Naeukeurige Beschrijvinge der Afrikaansche Gewesten van Egypten, Barbaryen, Libyen, etc. Amsterdam. 1668.

Montanus. A.

Gedenkwaerdige Gesantschappen der Oost Indische Maatschappij in 't Vereenigde Nederland aan de Kaisaren van Japan. Amsterdam. I669.

Baldaeus. Ph.

Naaukeurige Beschrijvinge van Malabar en Choromandel, derzelven aangrenzende rijken en het machtige eiland Ceylon; met Malabaarsche Spraakkunst. Amsterdam. 1672.

Piso. Willem, i6ri-i678.

Hij was eerst geneesheer te Leiden en Amsterdam en vergezelde later graaf Joan MaUrits van NAsSaU als lijfarts naar Brazilië, met hen ging ook GeorG van Marckgrave, een duitsche wis- en sterrekundige. JaN dE LAET gaf hun werk uit met zịn aanteekeningen.

Historia naturalis Brasilieae. (G. PIso, De medicina Brasil. - G. Marg-

- GRavi de I,iebstadt, Hist. rerum Natur. Brasil. Cum append. Jo DE LAEt.) I.ugd. Bat. et Amstelodami. 1648. 
Een 2e ed. hiervan verscheen onder den titel:

De Indiae utrinsque re naturali et medica libri XIV. Lugd. Bat. I6 58 . Veel van wat tot stand gebracht werd in Brazilië door J. M. van Nassau was spoedig weer verdwenen, doch de onderzoekingen op bevel van hem gedaan door Piso en Marckgrave zijn vastgelegd in bovengenoemde werken. Planten en dieren gestuurd naar Maurits' residentie werden beschreven en geteekend, zoo ook door Albert van DEN EeckHout, wiens Braziliaansche Uit bekend is geworden.

Piso gaf ook de werken van Bontius uit.

Nieuhof. Joan, I6I8-i672.

Gedenkweerdige Brasiliaense Zee- en Lantreize ...... met verscheide afbeeldingen, na 't leven aldaer getekent. Amsterdam. I682. (P.)

Met een opdracht aan Nic. WiTSEN en uitgegeven na den dood van JOAN, door zijn broeder Hendrik Nieuhof. Deze verzorgde ook de uitgave in 1665 (Ie druk) van:

Het Gezantschap der Neerlandtsche Oost-Indische Compagnie aan den grooten tartarischen Cham, etc. Amsterdam. In N.A.M. uitg. van I693. (P.)

Het werd vertaald in 't duitsch en latijn.

Bruyn. Cornelis De, I624-I7I9.

Verschillende personen o.a. NicolaAs WitsE., stelden hem in staat te reizen. Hij was een goed schilder en behalve landschappen, bloemen en dieren teekende hij ook portretten o.a. van de beide Gouv. Generaals Outhoven en van Hoorn.

Reizen door de vermaardste deelen van Klein Asia, de eijlanden Scio, Rhodus, etc. Delft. I698. (P.)

Reizen over Moskovie door Persië en Indië. Amsterdam. I7I4. (P.)

Witsen. Nicol.aAs, I64I-I7I7.

Burgemeester van Amsterdam. Deed yeel voor kunsten en wetenschappen. Hiji vestigde de aandacht op de overbrenging van de koffieplant naar Java en liet haar ook in de Amsterdamsche Hortus planten om bij mislukking, kiembaar zaad te hebben. ( $\mathrm{Z}$ ie GrESHOFF, hieronder).

Noord en Oost-Tartaryen, etc. Amsterdam. I785. (P.)

Greshoff. M., Nicolaas Witsen als Maecenas. I909. (Album der Natuur).

Roggeveen. Jacob, I659-I729.

Wat aan zijn vader, AREND, niet gelukt was, lukte den zoon Jacob pas op 62-jarigen leeftijd, n.l. iets meer te weten te komen van: de Stille of Zuidzee. Toch was deze ook niet fortuinlijk en na vele omzwervingen, waarbij hij o.a. het Paascheiland ontdekte, wou hij naar Batavia gaan. Door beslaglegging etc. werd hij gedwongen om weer naar Holland terug te keeren. Een jaar vóór zijn dood werd een zoogenaamd verhaal van zijn reis (niet door hem zelf) uitgegeven.

Twee jarige Reyze rondom de wereld ter nader ontdekkinge der onbekende Zuidlanden etc. Dordrecht. 1728.

Bogaert. Abraham, i663-i 727.

Historische Reizen door d' oostersche deelen van Asia. Amsterdam. I7I I. 
Heyman. Johannes, I667-I 737 .

Reizen door een gedeelte van Europa, klein Asien, verscheide eilanden van de Archipel, etc. Leiden. I757, $175^{8}$.

Twintig jaar na den dood van Heyman werden deze reizen uitgegeven door zijn neef Joh. Argid. van Egmond van den Neyenburg, die dezeifde streken bezocht had $1720-$ 1723. Deze werkte de twee reizen dooreen zoodat niet meer uit te maken is wat door HEYMAN geschreven is.

Bosman. Willem, I672-?

Nauwkeurige beschrijving van de Guinese Goud-, Tand- en Slavekust. Amsterdam. I709. (ie dr. I704). (P.)

Herlein. J. D. = J. D. H1.

Beschrijvinge van de Volk-Plantinge Zuriname. Leeuwarden. I7I8. (2e druk).

Nederi.andsche Reizen tot bevordering van den koophandel, na de meest afgelegen gewesten des aardkloots. Amsterdam-Harlingen. I784-1787. Hierin ook beschrijvingen over dieren.

Het gevolg van deze reizen was, dat de reizigers allerlei vreemde en merkwaardige voorwerpen van natuurhistorischen aard mecbrachten. Deze werden in dien tijd in Holland ijverig verzameld en de zoogenaamde „Kabinetten" ontstonden.

Zie hiervoor het artikel van H. ENGEL. Alphabetical list of dutch Zoological Cabinets and menageries. Bijdragen tot de Dierkunde. Ioo-jarig bestaan van N.A.M. 1939 .

Worm, Ole, I588-i654.

Museum Wormianum seu historia rerum rariorum, tam naturalium, quam artificialum etc. quae Hafniae Danorum in aedibus authoris servantur. Lugduni Batavorum. I655. (P.)

Olearius. Adam, I599-I67I.

Gottorfische Kunst-Kammer worinnen allerhand ungemeine Sachen, so theils die Natur, theils künstliche Hände hervorgebracht und bereitet. Schlesswig. I674.

RuYsch, Frederik, I638-i73I.

Thesaurus animalium primus. - Eerste cabinet der dieren. Lat. en Holl. Amsterdam. I7Io.

Vincent. LeVinus, i658-i727.

Wondertooneel der nature, geopent in eene korte beschrijving der hoofd- 
deelen van de zeldsaamheden daar in begrepen. Amsterdam. 1706. gevolgd door: Het tweede deel of vervolg van het Wondertooneel der Natuur, etc. I7I5.

Korte beschrijving van den inhout der Cabinetten begreepen in de Rariteitkamer, of wondertooneel der natuur. 1727.

Catalogus et descriptio animalium volatilium, reptilium en aquatilium, etc. La Haye. I726. Fransch-Latijn.

Description du Pipa, ou Crapeau aquatil de Surinam, avec une courte description des Grenouilles, etc. dans le Cabinet de ... Lat.-Franç. Haarlem. I726.

Al deze werken van Vincent zijn zeldzaam.

Seba. Albertus, 1665-i736.

Naaukeurige beschrijving van het kabinet der voorn. Seldzaamheden der natuur. (Thesaurus). Lat. Holl. Amsterdam. I734-i 765 .

Ditzelfde werk Lat.-Fransch. 1734-1765.

Natuurlijke zeldsaemheden in platen.

d.i. een verzameling van $82 \mathrm{pl}$. uit "Thesaurus", proefdrukken. De titel is in HS.

In de Catalogus I88I van N. A. M. is onder No. 3555 opgenomen een HS. van SEBA, wat onjuist is gebleken. Zie hierover: H. ENGEL in Tijdschr. v. Entomologie LXXX, 1937, Verslag 70e Wintervergadering en „Teekeningen” onder ELLIGER.

\section{Bloeitijd van de Anatomie.}

RuYsCh. FREDERIK, I638-I73I.

Thesaurus animalium. I-X. Amstelodami. (I709-'26).

Heide. Antonius de, I646-i6g6.

Ontdekker der later beroemd geworden trilbaarbewegingen.

Ontledinge der Mossels, en ontleed-genees- en heel kundige waarnemingen.

Uit het Latijnsch vértaald door F. J. v. Almei.oveen. Amsterdam. I684.

Albinus. Bernard Siegfried, i697-i 770.

Academicarum annotationum libri $\mathrm{I}-\mathrm{V}$, contin. anatomici, physiologici, zoographica, phytographica. Leidae. 1754-1761.

De dierenwereld in betrekking tot de Bijbel.

Bochart. Samuel, I599-i667.

Hierozoicon sive de animalibus sucrae scripturae. Lipsiae. 1793-1796.

Scheuchzer. Johann Jacob, 1672-I733.

Ofschoon Zwitser, werd dit werk toch in deze lijst opgenomen daar het indertijd zeker gewaardeerd werd en zijn invloed uitoefende, wat blijkt uit de Holl. vertaling van dit fol. werk in $\mathbf{5} \mathbf{5}$ dln door G. Tijssens en L. Paludanus. 
Geestelijke Natuurkunde. Uit het Latijn vertaald, met bijschriften in poëzy. Amsterdam. I735-i739. Met 750 pl. door J. A. Pfeffel.

BoerhaAve. JaCoB, ?-I752:

Een half-broeder van Herman BoerhaAve. Hij was predikant te Valkenburg bij Leiden.

Over den Behemoth en den Leviathan. Leiden. I737.

Walvischvangst.

Martens. Frederik,

Nauwkeurige beschrijvinge van Groenland of Spitsbergen, waarin de Walvisch-vangst ...... word aengewesen. Amsterdam. I7 IO.

Zorgdrager. Cornelius Gisbert, $\pm 1650-17$ ?.

C. G. Zorgdragers bloeijende opkomst der aloude en heedendaagsche Groenlandsche Visscherij, etc. Met bijvoeging van de Walvischvangst door Abraham Moubach. 2e druk. t’ Amsterdam. I728.

DE Walvischvangst met veele byzonderheden daartoe betrekkelijk. Amsterdam-HARLINGEN. I784.

Verder weer Chronologische Volgorde.

Renard. Louis, ?- voor I745.

Was agent van de koning van Frankrijk te Amsterdam:

Op het titelblad van het werk staat:

Poissons, Ecrivises et Crabes ... que l'on trouve autour des Isles Moluques et sur les Côtes des terres Australes ... Ouvrage ... qui contient un très grand nombre de Poissons ... de la Mer des Indes: divisé en deux tomes, dont le premier a été copié sur les originaux de M. B. CoyetT ... Le second tome a été formé sur les recueils de M. Adrien van Der STELl ... avec une courte description de chaque poisson. Le tout muni de Certificats et Attestations authentiques. Donné au public par Mr Louis Renard et augmenté d'une preface par Mr Arnout Vosmaer.

Amsterdam. 1754.

Op de titelbladen van $\mathrm{T} I-\mathrm{T} 2$ staat:

Historie naturelle des plus rares curiosités de la mer des Indes.

Complete exempl. zijn zeer zeldzaam.

Het werk werd lang na den dood van ReNard, door Vosmaer in 1754 uitgegeven terwijl RENAkn het tusschen 1718 en 1719 schreef. Hij zelf was nooit in Indië. In het Ie deel schijnt hij de teekeningen gebruikt te hebben die Cornelis de Vlaming uit indië meebracht, wat niet geheel klopt met wat aangaande COYETT op 't titelblad staat. De leekeningen van T. 2. zijn gemaakt door zekeren SAMUEL FaLLours, ziekentrooster t: Ambo:na. (Zie H. J. Veth. Proefschrift). 
Artedi. Peter, 1705-i735.

Ichthyologia sive opera omnia de piscibus. Vindic., recogn., caapt. et edid. C. Linnaeus. Lugd. Bat. I738.

Kerbert. C. Peter Arledi. I705-1735. Rede, uitgesproken bij de onthulling van zijn gedenkteeken in den tuin van het K.Z.G. „Natura Artis Magistra". Amsterdam. I905.

I.̈nNBerg. E. Peter Artedi. A bicentenary memoir, translated by W. E. HARLOCK. Upsala-Stockholm. I905.

Linnaeus. Carolus; i707-r 778 .

Slechts enkele werken uit de collectie werden opgenomen daar in Sept. I935, alle werken van en over Linnaeus, aanwezig in de bibliotheek van N. A. M., werden tentoongesteld (zie pag. I15) zie hiervoor:

Catalogue of the exhibition of books to be held in a locality of the R. Zool. Inst. „Natura Artis Magistra” II Linnaeana, exhibited on occasion of the bicentenary of Linné's „Systema Natura”. Ed. I. 1935.

We beperkten ons tot Linné's dissertatie, Ie en enkele andere drukken der Systema Natura, een paar portretten en facsimilis van brieven.

BASTER. JOB, ' I I I I-I 775 .

Opuscula subseciva de animalculis et plantis. Harlemi. I759-I760. (Hiervan alleen T. I. Liber I. 2.)

Natuurkundige uitspanningen, etc. Haarlem $1762-1765$. (I759 staat op Ie stukje en 1762 op het titelblad van re deel).

Maitland. R. T. De determinatie der dieren, beschreven en afgebeeld in de werken van Job Baster en Mart. Si.abber. (Tijdschr. Ned. Dierk. Ver.).

Vosmaer Arnout, 1720-i799.

Natuurkundige beschrijving eener uitmuntende Verzameling van zeldsaeme gedierten ...... levend voorhanden geweest zijnde, buiten den Haag op het kleine Loo ...... Amsterdam. (1766-) I804.

In het "Voorbericht” staat dat onder toezicht van VOSMAER de penteekeningen gemakkt werden door Schouman, HaAg e.a. en in 't koper gebragt door Simon FokKe. Oorspr. teekeningen in N. A. M. van A. Schouman, C. van KuYK, G. HaAsbroek en G. v. D. Heuvel. (Zie bij ,Teekeningen”).

Poissons, Ecrivisses et Crabes 1754 door Louis RenaRd, hiervoor schreef VOSMAer 't voorwoord en gaf het uit.

Catalogue de livres en plusieurs langues ... principalement d'histoire naturelle ... délaissés par feu; La Haye. I800.

BOMme. LeENDERT, I727-I 788 .

Waarnemingen omtrent de gesteldheid en groeying der Zee-Polypen. (Vert. Zeeuwsch Gen. der Wetensch. te Vlissingen. II. I77I. pag. 277). Verder bericht aangaande verscehidene Zee-Insecten, etc. (Idem IV. 1778).

Zie bij „Teekeningen". 
Gronovius. Laurentius Theodorus, i730-i777. P.

Museum ichthyologicum, sistens piscium indigenarum et quorumdam exoticorum etc. Lugd. Batav. I754-1756.

Bibliotheca regni animalis atque lapidei, etc.; in usum naturalis hstoriae studiosorum conscripta. Lugd. Batav. 1760.

Zoophylacium Gronovianum, exhib. Animalia quadrupeda, Amphibia, Pisces, Insecta, etc. quae in museo suo adservavit. Lugd. Bat. I78r.

Boddaert. Pieter, I730- I 796.

Over den gevlakten klipvisch. (Chaetodonte argo) Amsteldam. I770. Zie „Teekeningen" Dadelbeek.

Over de kraakbeenige Schildpad. (Testudine cartilaginea) Amsterdam. I770. Zie „Teekeningen” Dadelbeek.

Van den twee-koleurigen kikvorsch. (Rana bicolore) Amsterdam 1772. Zie „Teekeningen” Dadelbeek.

Van den tweedoornigen klipvisch. (Chaetadonte diacantho) Amsterdam. I772. Zie „Teekeningen” Dadelbeek.

Dit ziin beschrijvingen met afbeeldingen: Uit de verzameling van wịlen den Weled. zeer Greleerden Heere Johannes Albertus Schlosser. BoddaErT geeft deze beschrijvingen in brieven resp. aan Burmannus, Roüll, Oostrerdijk Schacht en Gaubius om het werk door Schlosser begonnen met een brief aan Ferdinand Dejean :

Over de Amboinsche Haagdis. (Lacerta amboinensi) Amsterdam. 1768.

te vervolgen.

Schlosser had reeds: verscheide meesterlijk uitgevoerde en zeer nauwkeurige teekeningen door de hand van den ervaaren Kunstschilder G. DADELBEEK verzameld" (zie Voorwoord bij Boddaert). Zie "Teekeningen” DadelbeeK.

Bovenstaande brieven zịn allen in druk verschenen, Lat.-Holl. tekst: N. A. M. bezit óók MS. van andere brieven van Boddaert. Zie „Handschriften”.

Natuurkundige beschouwing der dieren, in hun inwendig zamenstel, eigenschappen, huishouding, enz. Utrecht. 1778.

Boddaert vertaalde verscheidene werken van P. S. Pallas.

Phelsum. Murk van,

Medicinae Doctor, en Stads-Geneesheer te Sneek, staat vermeld onder zijn naam in: Brief aan ... Cornelius Nozeman ... Over de Gewelv-Slekken of Zee-egelen. Waar achter gevoegd zijn: Twee beschrijvingen ... van zeewier en andere van Maaden ... Rotterdam. I774.

I.IER. JAN VAN, ?

Verhandelingen over de Slangen en Adders, die in Drenthe gevonden worden. Holl.-Fransch. Amsterdam en Groningen. 178I.

Slabber. Martinus, I740-1835.

Natuurkundige verlustigingen, behelzende microscopische waarnemingen van in- en uitlandse water- en landdieren. Haarlem. I778.

Maitland. R. T. Determinatie der dieren, beschreven en afgebeeld in de werken van Job Baster en Mart. SiaAbber. (Tijdschr. Ned. Dierk. Ver.). 
Voornaamste entomologische werken omstreeks I8e eeuw.

Admiral. JaCob, L' r699-i 770 .

Nauwkeurige Waarnemingen van veele gestalt verwisselende, gekorvene Diertjes in omtrent 30 Jaaren ... vergaaderd, na het Leeven geschilderd, en nu in 't koper gebracht, door ... Alles door hem zelve uitgevoerd. Amsterdam. (1740-I 770 ?) met 25 (waarvan 8 gekl.) pl.

Pag. A. 2 begint met: Inschrijving tot het volgende werk, handelende over..... zie boven. Deze is niet geschreven door L'Admiral, waarschijnlijk door den Uitgever. Dan voigt: Korte verklaring der 8 eerste platen, daarna : Korte verklaring over acht platen, namentlijk van No. 9-16; daarna: Korte Verklaaring over negen platen, namentlijk van No. $17-25$.

Nauwkeurige waarneemingen omtrent de veranderingen van veele Insekten of Gekorvene Diertjes die in omtrent vijftig jaaren ... bij een verzameld zijn ... door wijlen den Heer ... 1774 .

Hiervan bezit N. A. M. 3 exempl. I met ongekl. platen, 2 met gekl. pl. (in beide ex. ontbreekt pl. xv).

In een exempl. de handteekening van JACOB L'ADMIRAAL 1744 onder de verklaring aan inteekenaar No. 105 van dit werk, dat 't niet hooger zal komen dan f 25. - als het voltooid is. (Zie „Teekeningen”).

Lyonet. Pieter. 1706-i 789 . P.

Traité anatomique de la Chenille qui ronge le bois de Saule ... La Haye. Amsterdam. I762.

Hierin, Fig. I, de mikroskoop door Lyonet gebruikt. Deze is in 't bezit van N. A. M. (zie „Microscopen”).

Recherches sur l'anatomie et les métamorphoses de différentes espèces d'Insectes, ouvrage posthume de P. Lyonet publié par M. W. DE HaAn. Paris. I832.

In het voorwoord door LYONET geschreven, pag. II, III, spreekt hij over een groot aantal insecten teekeningen; deze zijn nooit uitgegeven en velen daarvan zijn in 't bezit " vãn N.A. M. zie „Teekeningen”.

Hublard Emile. Le nautraliste hollandais Pierre Lyonet. Sa vie et ses œuvres ( I706--1789) d'après des lettres inédites. Bruxelles. x9ıo. (P.)

Trembley, Abraham, i7io-1784.

Mémoires pour servir à l'histoire d'un genre de Polypes d'eau douce, à bras en forme de cornes. Leide. 1744. (ingeplakt P.) $4^{\circ}$.

Dit zelfde werk uitgegeven in $12^{\circ}$. Parijs 1744 . De vignetten in de $4^{\circ}$ uitgave zijn geteekend door Cornelis Pronk (geb. I6ol) en gegraveerd door Jacobus vaN DER SCHLEY (1715-1775).

Lyonet teekende al de dertien platen der Polypen, de eerste vij f graveerde v. D. SCHLEY, doch de laatste 8 graveerde LyONET zelf. (Zie Teekeningen, Lyonet).

Instructions d'un père à ses enfants sur la nature et sur la réligion. Genève I775.

Pallas. Peter Simon, r741-i8i i.

Miscellanea Zoologica, quibus novae imprimus atque obscurae animalium species des crib. et observatt. iconibus que illustr. Hagae Comitis. 1766. 
Dierkundig mengelwerk, etc. uit het Lat. vertaald en met aanmerkingen door P. Boddaert. Utrecht. I770. Hetzelfde werk met gekl. pl.

Dierkundige beschouwingen, etc. vertaald ... opnieuw in 't licht gebracht. Rotterdam. z. jrtl.

Cramer. Pieter, ? - i 776.

De Uitlandsche Kapellen voorkomende in de drie Waereld-Deelen Asia, Africa en America. Holl.-Fransch. Utrecht. Amsterdam. 1779-1782.

Tot pl. 84 werkte CRAMER er aan, toen stierf hij. Er is een Aanhangsel bij waaraan CASPAR Stoll meewerkte.

Stoll. Caspar, ? - i 795 .

Behalve het genoemde Aanhangsel 179I, dat hij met P. CRAmer schreef, zie boven, is achter in dl. IV van de Uitlandsche Kapellen van zijn hand:

Proeve van eene rangschikking der Donsvleugelige insecten (1782).

Natuurlijke en naar 't leeven naauwkeurig gekleurde afbeeldingen en beschrijvingen der Cicaden ... Amsterdam. I788. (Holl. Fransch).

Natuurlijke ... der Wantzen. Amsterdam r788. Holl.-Fransch.

Natuurlijke ... der Spoken, Wandelende Bladen, Zabel-Springhanen, Krekels, etc. Amsterdam. I8I3. 2 dln. zie „Handschriften”.

Sepp. ChristuaAn, Goslar begin i8de eeuw -- 1775 .

Jan Christiaan, A'dam 1739-i8i i.

JAN, $\quad$ I778-I853.

CORnelis, $\quad$ I8IO-I868.

Allen waren boekhandelaar en uitgever te Amsterdam. Christiann begon het werk:

Beschouwingen der Wonderen Gods, in de minst geachte Schepzelen of Nederlands Insecten ... beschreeven, ... geteekent, in 't koper gebrarht en gekleurd door ... Amsterdam. J. C. Sepp. 8 dln. (I728-I860).

Hiervan is slechts dl. I. tekst en teekening ( I728-I762) van ChristiaAn. Al gauw kreeg hij hulp van zijn zoon.

Dl II (I763-'86) en III (I786-I8Io) en een groot deel van IV (I8Ioi82 I) zijn van dezen zoon Jan Christiaan.

De afbeeldingen zijn van Dl. I. Tab. VIII af, niet meer gesigneerd, doch door de verschillende Sepps geteekend. $\mathrm{Na}$ den dood van CoRnelis kwamen de teekeningen aen de Nederl. Entomologische Vereeniging.

D1 IV (I8Io-I82I) werd afgemaekt door JAN, eveneens dl V; VI, VII gedeeltelijk ( $182 \mathrm{I}-\mathrm{I} 855)$.

CoRnelis werkte niet als schrijver en teekenaar mee doch wel als uitgever en boekhandelaer. Tekst en teekeningen van VII en VIII werden verzorgd door S. C. Snellen v. Volienhoven, A. J. v. Eyndhoven, J. A. Herklots, Q. M. R. Verheul, E. A. de Roo van Westmaas, N. H. de GraAf en P. C. T. Snellen. 
Cornelis begon ook met de uitgave van de Flora Batava.

Voet. Johannes Eugenius. ? - I778.

Catalogus Systematicus Coleopterum Lat.-Fr.-Holl. tekst. la Haye. I806. N.A.M. bezit ook de editie die verschenen was tot Voet's dood, n.l. Bd. I, pag. I- 88 en Bd. 2 pag. I-24. Volgens een aanteekening in D1. I. 1806, is deze uitgave van 1766. Een andere aanteekening: „J. E. Voet. Insecta Coleoptera in Effigii Originali” verwijst naar Tab. XXVI-XL van Pars II. (Zie „Teekeningen”).

\section{WAARMOND.}

Ontdekking van de Staatkunde der natuur; of beschrijving van het wonderbaar gemeene best der Honing-Byen en zijde-wurmen, etc. 's-Gravenhage. 1789 .

\section{Vervolgens weer Chronologisch:}

Brandt. Joan CoenraAd, i703-iz9i.

Catalogus of naamlijst in drie taelen ( Holl. Franz.-Lat.) v. h. Kabinet Zeehoornen en doubletschelpen van ...

Dit is een duidelijk HS. met portret.

Catalogus van natuur en konst, bevattende een uitgebreide collectie van Hoorens en doublet-Schelpen etc. Bijeengebragt door ... (Holl. Franz.) Amsterdam. I792.

Hierin namen van koopers en prijzen.

Houttuyn. Martin, i720-

Natuurlijke Historie of uitvoerige beschrijving der Dieren, Planten en Mineraalen, volgens het samenstel van den Heer Linnaeus. Amsterdam. I 76I-I 785.3 dln. 37 stuks.

N. A. M. bezit hiervan een ex. met gekl. pl. en $\mathrm{I}$ ex. met ongekl. pl. Houtruyn vervolgde Nozeman en Sepp's Nederlandsche Vogelen.

Nozeman. Cornelis, I72I-I 785 . Nederlandsche Vogelen, volgens hunne huishouding, aert, en eigenschappen, beschreven door ... Amsterdam. I7701829. (zie „Teekeningen”. Sepp.).

Camper. Petrus, i722-i789.

Natuurkundige Verhandelingen over den Orang-outang ...over den Rhinoceros met den dubbelen Horen; en over het Rendier. Amsterdam 1782.

Titelblad met HS. v. d. Auteur.

Fistola ad Blumenbachi in metamorph. Bufonis pipae. 1788.

Description anatomique d'un éléphant mâle par Pierre Camper, publiée par son fils A. G. Camper. Paris I802.

Twee penteekeningen uit dit werk, geteekend J. CAMper. f. ad. archetypum Patris an: 1774.

Catalogue de Manuscrits de ... Amsterdam. I88I.

Observations anatomiques sur la structure interieure et le squelette de plusieurs espèces de Cetacés. par P. CAMPER publiées par son fils 
Adrien Gilles Camper avec des notes par M. G. Cuvier. Paris i820. daarbij: Recueil de planches ... par M. M. Camper. Pł̀re et fils. Paris. 1820. (Zie „Teekeningen”).

Berkhey. Johannes le France van, 1729-1812.

Natuurlijke Historie van Holland. I2 dl. Amsterdam. Leiden. I769-I8I I.

Catalogus librorum medicorum, anatomicorum et miscellaneorum. Quos inter excellences libri quidam rariores et nonnulla MSS. Lugd. Batav. I783.

Eerste Catalogus van de uitgebreide ... Natuurkundige Verzameling van ... Amsterdam. 1784 .

Tweede, Derde en Vierde 'Catalogus etc. Amsterdam. I785.

Martinet. Johannes Florentinus, i729-i795. P.

Dissertatio philosophica inauguralis de respiratione Insectorum. Lugd. Batav. I753.

Katechismus der Natuur. 1782-1789.

Verhandeling over de Natuurlijke Historie von ons Vaderland. Amsterdam. I795.

Bennet. Jan Aarnout, $175^{8-1828 .}$

en

Olivier. Gerrit van, 1759-i 827 .

Handboek der Natuurlijke Historie. Uit het hoogduitsch door ... Leyden. 1802.

Over de Nederlandsche Dieren. Amsterdam. I825, I826.

Naamlijst van Nederl. Visschen. 1824 .

Naamlijst van Insecten. . $\quad 1824$.

Wormen in Nederland aanwezig 1826 .

Brugmans. Sebald Justinus, i763-i8ig.

Lithologia Groningana Lugd. Batav. I787.

Catalogue de la bibliothèque de botanique, d'histoirie naturelle, etc. de feu. Leide. 1858 .

Frémery. NicolaAs Cornelis de, I770-I844.

Bijdrage tot de kennis der fossile Zoogdieren, in N. Nederland gevonden. Amsterdam. I840.

Catalogue des Musées d'histoire naturelle et d'anatomie comparée, délais-

- sés par ... Utrecht. 1856.

BakKer. Gerbrand, I771-I828.

Osteagraphia piscium. Groningae. 1828 .

Reinwardt. Caspar Georg Garl, 1773-i854.

Oratio de Chemicae et Hist. Nat. studiis recte instituendis. Amsterdam. 1810. 
Catalogue des livres ... geologie, botanique, Zoologie, .médécıne ... qui composaient la Bibliothèque de ... Leyde. 1855 .

Verder nog botanische werken. In Indië zijnde waren hem o.a. de teekenaars A. J. en J. T. BIK toegewezen. Zie "Teekeningen”.

VETH. H. J. Overzicht van hetgeen, in het bijzonder door Nederland, gedaan is voor de kennis der fauna van Ned. Indië. Proefschrift. Leiden I879.

Sirks. M. J. Indisch natuuronderzoek. Proefschrift. Koloniaal Instituut Meded. IV. 1915.

Vrolik. Gerardus, 1775-1859. P.

Over een zonderling gebrek in de huid ... bij een eerstgeboren kind. Amterdam I84I. Waarnemingen en proeven over de ... ziekte der aardappelen. Amsterdam. 1845 .

LEENDERT ВоммE (zie aldaar) verklaard voor eersten ontdekker v. d. werktuigelijke wijze waarop Pholaden in steen bouw. 1853 .

Catalogue de la bibliothèque d'hist. nat. de médécine, etc. délaissée par ... Amsterdam I860.

Dusseau, J. L. Musée Vrolik. Catalogue de la collection d'anatomie humaine ... de G. W. Vrolrk. Amsterdam. I865.

Anslijn. NicolaAs, I777-I 838 .

Systematische beschrijving der meest belangrijke voortbrengselen der drie rijken der Natuur. Leyden. $1822-1836$.

Temminck. Coenraad Jacob, I778-i858. P.

Histoire naturelle générale des Pigeons; avec fig. en couleurs, peintes par Pauline de Courcelles. Paris. I808.

Histoire naturelle générale des Pigeons et des Gallinacés: Amsterdam. I8I3-I8I5.

Manuel d'ornithologie, etc. Amsterdam \& Paris. I8I5.

en nog vele andere werken.

Hij bezat een beroemde vogel collectie, die zijn vader JACOB begonnen was. TEMminck interesseerde zich zeer voor N. A. M. en was bevriend met G. F. Westerman.

W. VRolik. Levensbericht van C. J. Temminck. Amsterdam. I858.

$Z i j$ die gestuurd werden door „de Natuurkundige Commissie voor Nederlandsch-Indie".

KuHL. Heinrich, I797-I82I.

Responsum ad questionem: Cum licet naturae vario mado corpora inter se differant, etc. ( $187 \mathrm{I}$ ).

Dit was het antwoord op de prijsvraag door de Groningsche philos. faculteit uitgeschreven, waarmee Kuhl de gouden en van Hasselt de zilveren eerepenning behaalde.

Uittreksels uit brieven aan Tеммілск over de nat. hist. van Java. I820.

Vita Henrici Kuhlit z. j.

Hasselt. Johan Coenraad van, 1797-1823.

Responsum ad questionem, etc. Zie hierboven bij Kuhl. 
Dissertatio exhibens observationes de metamorphosi quarundam partium Ranae temporariae. Groningae. 1820.

Uittreksel uit een brief aan Prof. v. Swinderen over nieuw ontdekte Mollusken Java's.

(Zie verder „Handschriften”).

Boie. HeINRICH, I794-I827.

Brieven door Boie en Macklot van Java aan C. J. Temminck. I826.

Kenteekenen van eenige Japansche Amphibiën. Amsterdam. I826.

Uittreksels uit de berigten van de Heeren Bole en MAcki.ot door W. DE HaAn. z.j.

Briefe von Heinrich Boie ... Schleswig. I832.

Susanna. J. A. Levensschets van H. Boie. I828 (P.)

- , Levensschets van $\mathrm{H}$. Boie en hulde aan zijne deugden, etc. Amsterdam. i 834 (P.)

Zie verder „Handschriften”.

Susanna. H. J. ?

Verslag van de belangelooze pogingen door onze Nederlandsche reizigers, in de laatste tijden ten nutte der wetenschap aangewend. I828.

(Zie BorE).

PEL. H. S. ?

Aanteekeningen gehouden op eene reis van St. George Delmina naar Comassie, etc. 1842 .

MACKLot. H. C. ?

Uittreksels uit: Brieven van Macklot aan Dr C. J. Temminck en J. A. Susanna.

Uittreksels uit de berigten v. d. Heeren Boie en Macklot door W. DE HAAN. z.j.

Korthals. P. W. ?

Verhandelingen over de natuurlijke geschiedenis der Nederl. Overzees the bezittingen. Uitgeg. door C. J. Tеммілск. Leiden. I833---J844.

Botanie door P. W. Korthals.

Aanteekeningen uit een brief aan J. A. Susanna te Leiden. z.j.

Zie „Handschriften").

HörNER. L. ?

Geologische en mineralogische aanteekeningen over het eiland Borneo. z.j.

Chronologisch Vervolg.

SANDIFORT. GERARD, I779-I848.

Tabulae craniorum diversarum nationum. Lugd. Batav. 1838 .

Veth. Huibert Johannes,

Overzicht van hetgeen, in het bijzonder door Nederland, gedaan is voor de kennis der fauna van Nederl. Indië. Leiden 1879. 
Swinderen. Theodorus van, I782-I85I.

Overzigt over de Zoogdieren, tot leiddraad bij de akademische voorlezingen. Groningen. I820.

Index rerum naturalium in Museo academico Groningano. (Lat. Ned.) Groningen. I822, und Fortzetsung I-4, 6-I6. (I823-I848).

Verheull. Quiryn MaUrits Rudolf, I787-i860.

Handboek voor liefhebbers en verzamelaars van Vlinders. Rotterdam. I842. (Zie „Teekeningen").

Jeude. Theodorus Gerard van Lidth de, i788-1863.

Oratio de Jo Swammerdamio. Trajecti ad Rhenum. I820.

Recueil de figures des Vers intestinam. Leide. I829.

Met gekleurde platen, zeer zeldzaam.

Naamlijst v. d. geslachten der Zoogdieren. Utrecht. 1837.

Catalogue du Musée Zoologique P. I. 2. 4. Amhem. 1858 .

Catalogue de la bibliothèque d'histoire nat. médécine, etc. de feu. Amsterdam. I 866.

(Zie „Handschriften” en "Teekeningen” ook bij Maitland").

Breda, Jacobus Gijsbertus Samuel van, I788-1867.

Oratio de educatione vero liberali et hist. nat.studio. etc. Leovardia. I8I8.

Catalogue de la bibliothèque de géologie et ... d'histoire naturelle ,etc. de feu. Leide. 1868 .

Mulder. ClaEs, I796-i867.

Mededeeling over het fosfiel gewoon hert 1855 .

Bijdrage tot de kennis v. d. Veenmol. 1858.

En vele andere in periodieken.

Kolk, Jacobus Ludovicus Conradus Schroeder vaN Der, I797-I862.

Bijdrage tot de anatomie van den Stenops kukang. Leiden. I84I.

Mémoire sur l'Anatomie et la physiologie du Gastrus equi. Amsterdam. I845.

Altena. H. L. van ?

Enumeratio systematica species indigenae reptilium ex ordine Batrachiorum, etc. Lugd. Batav. I829, I830.

Vrolik. Willem, i80i-is63. P.

Commentatio de auditus organo cum hominis tum animalium. Trajecti ad Rhenum. I822.

Recherches d'anatomie comparée sur le Chimpansé. Amsterdam. I84I.

Het leven en maaksel der dieren. A'dam. I853- I860.

En veel andere.

Hoeven. J. van der. Levensbericht van Will.em Vrolik. Amsterdam. I864. 
Dusseau, J. L. Musée Vrolik. Amsterdam. 1865.

Redevoering ter opening van dierkundige voorlezingen, gehouden voor de leden van het Gen. N. A. M. Amsterdam. I893.

Voorlezing ten behoeve van de H.H. leden v. h. Gen. N. A. M. I2 Mrt. I840. Amsterdam.

$\mathrm{Hij}$ had een groote belangstelling voor N. A. M. en hield verschillende lezingen voor de leden van dit Genootschap.

HaAn. Wilhem de, I80i-I855. P.

Fauna Japonica. Ph. Fr. v. Siebold; Invertebrata. W. de HaAn. Lugd. Bat. $1833-1850$.

Jyonet. P. Recherches sur l'Anatomie et les métamorphoses de différentes espèces d'Insectes; ouvrage posthume, publ. par. W. DE HaAN. Paris. I832.

Catalogue d'une collection choisie de livres d'histoire naturelle, principal d'entomologie. Leide. 1855 .

(iZe „Handschriften").

Hoeven. Jan VAN DER, I8OI-I868.

Beknopte handleiding tot de geschiedenis van het dierenrijk. Haarlem. I835.

Handboek der Dierkunde. 2e verm. uitgave. Amsterdam. I849-55. Met atlas.

Doorschoten en met aanteekeningen van Prof. W. Vrolik.

Oratio de aucta et emendata Zoologia post Linnaei tempora. Lugd. Bat. 1843 .

Met opdracht in HS. v. d. Hoeven.

Bonaparte. Charles (Jules Laurent) Lucien, Prins van Canino. i803 $-\mathrm{I} 857$.

Hij kwam in aanraking met Temminck, Schlegel en Westerman.

Observations on the nomenclature of Wilson's Ornithology. Philadelphia. I826.

Met een opdracht van den auteur aan Temminck.

Conspectus systematicus ornithologicus. Edit. reform. additis synonymis Grayanis et Selysanis. I850.

Schlegel. Herman, I804-r884.

Essai sur lai physionomie der Serpens. La Haye. I837. (Zie „Teekeningen”).

Abhandlungen aus dem Gebiete der Zoologie und vergleichende Anatomie. Leiden. 184I-r843. Heft r. 2. (Über die Cetaceen).

De Diergaarde en het Museum van het Genootschap „Natura Artis Magistra" te Amsterdam. Amsterdam 1842. I ex met gekl. en I met ongekl. pl.

Die Tag-Raubvögel Europa's. 1842. (Geen titelblad). 
Abbildungen neuer oder unvollständig bekannter Amphibien, etc. Düsseldorf 1837-i844. (Zie „Teekeningen”).

Over de vereischten van natuurkundige afbeeldingen. Haarlem. I849 (bekroonde prijsvraag, zie“"Handschriften”).

De Zoogdieren; handleiding voor het onderwijs, enz. Amsterdam. 1852.

De Vogels van Nederland. Leiden. 1854-1858. (Zie „Teekeningen”).

Handleiding tot de beoefening der Dierkunde. Breda. I857. 1858 .

De Dierentuin van het K. Z. G. „Natura Artis Magistra” te Amsterdam. A'dam. I863-i872.

De Toerakos, afgebeeld en beschreven door H. Schlegel, onder medewerking van G. F. Westerman. Amsterdam. I860.

Dit is een uitgave van het K. Z. G. Natura Artis Magistra, een groot folio formaat met gekl. (of ongekl.) platen.

Natuurlijke Historie van Nederland, Haarlem, hiervan door H. Schlegel, Dieren van Nederland; Gewervelde dieren 1860-1862.

Nederlandsch Tijdschrift voor de Dierkunde, onder redactie van P. BLEEker, H. Schlegel en G. F. Westerman. Dl. I-V. I ; I863-i884. Uitgeg. door N. A. M.

De Vogels van Nederl. Indië. Holl. Fransch. Haarlem. 1863-1866. Verder nog vele artikelen in verschillende periodieken.

Levensberichten :

Schlegel. G. Levensschets van...... A'dam. I 884 .

Snelleman. J. F.: H. Schlegel. Haarlem. I884.

Hubrecht. A. A. W. : Prof. H. Schlegel (de Gids) 1884.

Schubaert. Toers, Diesbergen, I805-i854.

Tafel van den ouderdom des Paards, etc. Utrecht. I84I.

Verloren. M. C. Levensschets van ...... Utrecht. 1854 .

(Zie.,'Teekeningen” en „Handschriften').

Harting. Pieter, i8i3-i885.

Het Mikroskoop, deszelfs gebruik, geschiedenis en tegenwoordige toestand. 3 dln. Utrecht, Tiel I848-I854.

Het eiland Urk, zijn bodem, voortbrengselen en bewoners. Utrecht. I 853 . Mikroskopische voorwerpen uit beide organische rijken. Tiel. I854.

40-jarig jubilée van ......

Catalogue de la Bibliothèque, d'histoire naturelle, Ethnographie de ...... avec prix. Leiden 1886.

Hnbbrecht. A. A. W. Harting herdacht. Amsterdam. 1886.

Bleeker. Pieter, I8I9-i 878 .

Een groote hoeveelheid separaten uit verschillende periodieken.

Atlas Ichthyologique des Indes Orientales Neerlandaises. Amsterdam. I862- 1876 . 
Catalogue des Collections, formée et laissée par M. P. BLEEkER. Leiden. 1879 .

Hierin cen voorwoord van Hubrecht.

Pollen, François, ?

Mémoires scientifiques. St. Denis. 1866.

Recherches sur la faune de Madagascar ... Leyde. I867-187i. Ie Partie. Relation de Voyage. Een blik in Madagascar. Leyden. 1867.

Herklots. Janus AdriaAn, I820-1872.

Bouwstoffen voor een Fauna van Nederland. Verzameld door ... Leyden. $1853-1866$.

Symbolae 'Carcinologicae. Etudes sur la classe des Crustacés. Leyde. 1861.

Catalogue des livres d'hist. nat. et de médécine de ...

Hall. Herman Christiaan, I826-187i.

Hoof dtrekken der Natuurlijke Historie van Noord Nederland. z.j.

Oratio de Neerlandia, Histor. Natur. ex colendae, etc. Groningae. I837.

Jentink. Frederik Ânna, ï844-igiz.

zie voor zijn publicaties: Notes from the royal zoological Museum of the Netherlands at Leyden. Leyde. 1879.

FürbRINGER. MAX, I846-1920.

Untersuchungen zur Morphologie und Systematiek der Vögel, zugleich ein Beitrag zur Anatomie der Stütz- und Bewegungsorgane. 2 Th. I888. (Bijdr. t. d. Dierk. XV).

Maitland. R. T. ? - I904.

Alphabetische Naamlijst der Nederlandsche Vogelen.

Dit is MS. : Aanteekeningen op Bouwstoffen voor een Fauna van Nederland.

Fauna Belgii Septentrionalis. Systematische beschrijving der dieren, welke in Noord Nederland voorkomen. Lat. Holl. Lugd. Batav. I85I.

Prodrome de la faune des Pays-Bas et de la Belgique flamande. Leide. 1897. Notices sur les animaux rares des Pays-Bas et de la Belgique flamande. (Mammifères) La Haye. I 898.

(Zie „Teekeningen” ook bij v. Lidth de Jeude).

Kerbert. Coenraad, i849-1927.

Werd geboren te Monnikendam 24 Jan. 1849. Te Leiden doorliep hij de Lagere School en te Amsterdam eerst de Fransche School van $\mathrm{Mr}$ Patoir, en daarna het Gymnasium. Oook studeerde hij aldaar aan het Athenaeum Illustre en te Leipzig aan de Universiteit waar hij een leerling was van LeuckarT. In 1876 promoveerde hij te Leipzig :

Über die Haut der Reptilien und andere Wirbelthiere. Bonn. 1876.

In 1877 werd hij assistent bij Prof. Berisn aan het Zoologisch Laboratorium v. d. Univessiteit van Amsterdam, 1883 privaat docent, en 1885 lector in de Zoologie. In 1878 werd hij benoemd tot leeraar aan de Kweekschool voor Onderwijzers te Amsterdam. In N. A. M. werd een nieuw Aquarium gebouwd waar Kerbert "1882 hoofdconservator werd, totdat 2 Juni 1890 zijn benoeming tot directeur van N. A. M. volgde. Dit bleef hij tot zijn dood 8 Sept. 1927. Zie verder: 
M. Weber. In memoriam Dr Coenraad Kerbert. (Vakblad v. Biol. IX. IX. pag. 26).

Veel van Kerbert's werk is gepubliceerd in de Bijdragen tot de Dierkunde, Ned. Tijdschrift Dierkundige Ver., Ardea, Zoolog. Anzeiger, e.a.

Man. Johannes Govert, DE $1850-1930$.

N. A. M. kreeg in 1930, na den dood van Dr. J. G. de Man, diens geheele verzameling biologische bockwerken ten geschenke waaronder ook al hetgeen door hem zelve gepubliceerd was. Dit is samengevat in:

Publications scientifiques au docteur J. G. de Man depuis l'année I873 jusqu'a 1923 (de rest is bijgeschreven).

Hierbij bevinden zich ook teekeningen en manuscripten van zijn werk.

Hier zij nog eens gewezen op de uitgebreide literatuut over Decapoden en Nematoden, die in 't bezit was van DR J. G. DE MAN.

Hoers. Paulus Peronius Cato, i85i-igi4.

Eerste bijdrage tot een nauwkeuriger kennis der sessile Cirripediën. Leiden. 1875 .

Cirrepedia of the Siboga Expedition. Siboga Exped. Leyden. I9I3.

Verder nog vele publicaties in: Tijdschr. Ned. Dierk. Ver., Niederl. Archiv für Zoologie, Compte-Rendu Acad. d. Sc. Paris, etc.

Weber. Max. Wilhelm C.ARL, I852-I937.

Die Nebenorgane des Auges der einheimischen Lacertidae. Bonn. I877.

De re public. over de Nederl. Fauna:

Rana arvalis Nilsson, eene voor de Nederl. Fauna nieuwe soort. I878.

De kleuren der dieren, haar ontstaah en hare beteekenis. I883.

Die Säugetiere. Jena. I904. en Jena. 1927.

The Fishes of the Indo-Australian Archipelago. Leiden I-VII. I9II1936. in samenwerking met L. F. de Beaufort.

Verder nog vele publicaties in periodieken.

Voor „Het Wetenschappelijk van Max Weber" zie Art. van L. F. DE BeAUfort in Vakblad voor Biol. XVIII. pag. I25. 1937.

Op een enkele na, bezit N.A.M. al de hierin genoemde werken.

Hubrecht. Ambrosius Arnold Willem, i853-i9i5. P.

De hypothese der versnelde ontwikkeling door eerstgeboorte en hare plaats in de evolutieleer. Leiden. 1882.

The descent of the Primates. New York. 1897.

Hoffmann. Christiaan Karl, I854-I903.

Vergelijkende ontwikkelingsgeschiedenis van de Gewervelde Dieren. I. Leiden. $\mathrm{I} 884$.

Sluiter, Carel. Philip, I854-I935.

Bijdrage tot den bouw der kieuwen van Lamellibranchiaten. Leiden. I878.

De dierlijke parasieten van den mensch en van onze huisdieren. 's-Gravenhage I894. Amsterdam. I9I2. 
Die Holothurien. (Siboga Exped.).

Artikelen in verschillende periodieken.

Vosmaer. Gualtherus 'Carel. Jacob, I854-igi6.

Aanteekeningen over Leucandra Aspera. Leiden. I880.

Welke Periodica Zoologica kunnen in de Nederlandsche openbare bibliotheken geraadpleegd worden?' 's-Gravenhage. 1898 .

Horst. Rutger, ?- +

Aanteekeningen op de Anatomie van Lumbricus terrestris. Utrecht. 1876.

HAar. Dirk ter, 1860-I905.

Onze Vlinders. Zutphen. 1904.

Oort. Eduard Danifl van, I876-i933.

Ornithologia Neerlandica. De vogels van Nederland. 's-Gravenhage. 1922-1935. $5 \mathrm{dln}$.

Kampen. Pieter Nicolaas, i878-i937.

De tympanaalstreek van den Zoogdierschedel. Amsterdam. I904.

Periodieken uitgegeven door het Kon. Zool. Gen. „NATURA ARTIS MAGISTRA".

JaArboekje van het K. Z. G. „Natura Artis Magistra”. $1855-1875$.

Nederlandsch Tijdschrift voor de Dierkunde, onder redactie van

P. Bleeker, H. Schlegel en G. F. Westerman. Ie jaargang-5e jaargang, Af1. I. I863-1884.

Bijdragen tot de Dierkunde.

D1. $\mathrm{I} \rightarrow$. $\mathrm{I} 848 \rightarrow$.

Het Feestnummer v. h. 50-jarig bestaan v. h. Genootschap, 1888, heeft geen vervolgnummer.

\section{OORSPRONKELIJKE TEEKENINGEN}

N. A. M. bezit een groote collectie oorspronkelijke teekeningen. Deze werden meestal gekocht of ten geschenke ontvangen, omdat het onderwerp, de zoologie, of historisch, den tuin betrof; ook uit aesthetisch oogpunt zijn de meesten de moeite waard.

Veel van deze oorspronkelijke teekeningen behooren bij de afbeeldingen genoemd in het artikel van R. T. MaItland in de Bijdragen tot de Dierkunde. I888, pag. 22. Hij beschrijft hierin het dcel van deze verzameling afbeeldingen van alle diersoorten, begonnen door Th. G. van LidTh de JeUde en door hem voortgezet. 
Van deze 60.000 stuks afbeeldingen, ondergebracht in 226 doozen, zag ik de verzameling tot nu toe slechts na op oorspr. teekeningen, van de ProtozoA TOT DE VERTEBRATA.

Het grootste deel is hiervan gesigneerd, doch veel is onbekend. Er zijn veel teekeningen geheel uit- of heel klein afgeknipt, omdat er vlak naast een andere teekening stond. (bijv. Voet).

De lijst die hier volgt is een alphabetische volgens de teekenaars.

Admiral. Jacob L'

Amsterdam. 'I699-12 Sept. I770.

De voorouders van JACOB en zijn broer JAN ${ }^{1}$ ) kwamen uit Normandië. Beiden werden opgeleid voor de schilderkunst en werkten daartoe o.a. bij $\mathrm{L}_{\mathrm{E}}$ BLON te Londen. Terug in Amsterdam hield JACOB zich meer dan 30 jaren op, met de gedaanteverwisseling bij insecten. Al zijn nauwkeurige waarnemingen teekende hij even nauwkeurig en bracht deze op koper.

Daar zijn beroep als IJkmeester-Generaal hem evenwel weinig vrijen tijd liet, waren bij zijn dood slechts 33 van de 70 platen klaar gekomen.

In 1774 verscheen door toedoen van M. HoutTuYs het werk met 33 handgekleurde platen.

In 1740 waren echter reeds 8 stuks uitgekomen, naderhand weer 8 en daarna nog eens 9; deze bij elkaar, is de uitgave $1740-1770$ ? genoemd bij „Auteurs”. Er waren toen nog 8 pl. gereed, deze werden gebruikt door HoutTuyn in zijn Natuurlijke Historie, etc.; met toestemming van L'ADmiral. Deze 8 voegde Houttuyn toe bij de uitgave van i774.

N. A. M. bezit Contra épreuves van l'Admiral's werk en wel de eerste 25 (XII mist) dus die van I740-I770 ?. Ze zijn héél mooi met de hand gekleurd, mooier dan in de werken zelf. Daar ze verspreid lagen in de verschillende exemplaren kon ik niet meer nagaan of ze oorspronkelijk in de Ie uitg. behoorden.

Ast. Bartholomeus, van Der

begin I $\mathrm{Ie}$ eeuw.

Hij was een Utrechtsche schilder van bloemen en vruchten waar hij dan insekten, schelpen, waterdroppelen etc. bij teekende.

In N. A. M. 26 st. teekeningen van schelpen, waarbij een gedateerd I660 terwijl zijn sterf jaar ongeveer 1656 gesteld wordt.

Bik. Adrianus Johannes, Duinkerken I3 Jan. I790-I Oct. I872, Brussel. James Theodoor, A'dam I4 Juni I796-3 Juli I875. Buitenzorg.

Beide artistieke, begaafde kunstenaars waren teekenaars voor 't werk van REINWARDT, een belangrijk dagboek van zijn laatste reis, dat na zijn dood (27 Dec. 1827) gevonden en uitgegeven werd.

In N. A. M. een gekleurde teekening van Simia leuciscus.

I) JAN legde zich toe op anatomische teekeningen; hij teekende voor AlBINUs en RuYSCH. 
BOMME. LEENDERT,

Middelburg 20 Febr. 1727-20 Maart 1788. Middelburg.

Hij was opgeleid voor den handel, werd een bekend koopman te Middelburg en bekleedde allerlei functies, die hem zeer in beslag namen. Naast dit werk ging echter zijn belangstelling uit naar natuur- en sterrekunde en vooral natuurlijke historie. In de Verhandelingen uitgeg. door het Zeeuwsch Genootschap, zijn verschillende artikelen van zijn hand o.a. over ZeeInsecten. Dl. VI I778. pag. 357; over een zonderling zespen-nestje Dl. VII. I780. pag. 213, 225 en 226. De afbeeldingen hierbij zijn door L. ВомME geteekend en N. A. M. bezit de origineelen hiervan.

Dat ook de teekenkunst zijn belangstelling had, blijkt uit de rede waarmee hij I I Dec. I 777 het Teekencollege te Middelburg inwijdde en de aandacht die hij steeds had voor de Teekenakademie.

Zijn teekeningen, boeken en portretten werden I 788 te M'burg verkocht.

\section{BronkHORST. JOHANNES, VAN}

\section{Leiden 1648-}

Vroeg verloor hij reeds zijn vader, zoodat zijn moeder hem, op I3-jarigen leeftijd, bij een neef, die pasteibakker was te Haarlem, dat vak liet leeren. Van kind af voelde hij zich aangetrokken tot teekenen en schilderen, doch pas nadat hij in I670 gehuwd was en in Hoorn gevestigd, kon hij zich aan deze kunst wijden. Dit deed hij echter in zijn vrijen tijd, maar met zóón toewijding en ijver, dat hij zonder onderwijs gehad te hebben, toch onder de goede schilders gerangschikt wordt.

$Z$ ijn beroep bleef hij hiernaast steeds uitoefenen, en dat dit geen slechte manier van geld verdienen was, bewijzen de leerlingen, die hij, zoowel in de schilderkunst als uitspanning, als in het pasteibakken als kostwinning moest onderwijzen.

N. A. M. bezit een waterverfteekening van eenige vogels.

Bruyn. J. C. DE,

begin rge eeuw.

Door den koning was hij als teekenaar der Natuurkundige Commissie benoemd, doch werd spoedig vervangen door P. vaN OORT.

In N. A. M. zijn verscheidene aquarellen, reptielen. Hierbij origineelen van het werk van REINWARDT, 3 stuks gedateerd I829 en I830, allen gesigneerd. Op een daarvan staat opgegeven: Peintre de fleurs à Utrecht. Il a dessiné des objets d'histoire naturelle pour le Prof. Bleuland. re moitié du XIXme siecle.

I ex. (Boa) teekende hij uit de verzameling van van KLINKEnBERG. I826. I ex. Inlandsche Hagedissen, die onder toezicht van BoIE geteekend werden. Verder nog 2 st. reptielen ex aucht. bibl. Prof. Schlegel. 
Camper. Petrus,

Leiden II Mei 1722-7 April I789 's-Hage.

Deze veelzijdige mensch was hoogleeraar in de wijsbegeerte, genees- en heelkunde en lid van de Raad van State. Behalve een goed spreker was hij ook een talentvol teekenaar. $\mathrm{Hij}_{\mathrm{j}}$ was een leerling van KAreL Moor en I6 jaar oud makte hij reeds olieverf schilderijen.

N. A. M. bezit 2 penteekeningen van zijn werk: Description anatomique d'un éléphant mâle. I802. (zie „Auteurs") en 3 rood-krijt teekeningen: Études de l'Eléphas inäicus. A la sanguine. 3 Feuilles dont une est signé: P. Camper. f. Io Sept. i 786.

Dadelbeek. G.

?-?

Volgens v. d. Aa. Biografisch Woordenboek: „DADELBEEK was een verdienstelijk teekenaar, wiens voornaam en levensbijzonderheden onbekend zijn, doch van wien teekeningen voorkomen in den Catalogus van Gerrit BraAmcamp te Amsterdam in I7II".

De waterverf-teekeningen in bezit van N. A. M. zijn duidelijk gesigneerd G. DADELBEeK, 7 er van gedateerd I769.

4 stuks behooren bij den tekst door P. BoddaERT (zie „Auteurs”) n.l. uitgegeven brieven over: den gevlakten Klipvisch 1770; de kraakbeenige Schildpad I770; van den twee-koleurigen Kikvorsch 1772; van den twee doornigen Klipvisch 1772.

2 stuks behooren zeer waarschijnlijk bij MS. brieven, (zie „Handschriften”) n.l. over: de geharnasten Klipvisch of Chaetodonte clypeato (*Teuthis (Amphacanthus)); de gevleugelde Roch of Raja alata (*Myliobatis). 4 stuks *Gobius; *Raja v. boven en van onder; *Rhinobatis v. boven en v. onder.

DraAk, Rijndert Willebrordus,

Geteekend portret van ......

Leerling van TемміNCK, die zich groote verdiensten had verworven in het opzetten van dieren, ja zelfs in het zoo moeilijke, conserveeren van visschen, was suppoost in 't Amsterdamsch Burger-Weeshuis, waar hij een der uitgestrekte zolders allengs in een museum van natuurlijke historie herschiep. Dit museum is later overgebracht naar de Nieuwe. Stads Herberg in de Plantaadje en werd in den zomer van 1837 voor het publiek geopend. Draaks 'Museum is bij een acte van den 15 Oct. 1838 in eigendom overgegaan aan het Genootschap N. A. M.

Elliger Sr. Ottomar, Göteborg 1633-3i Dec. i679 Berlijn.

Elliger Jr. Ottomar, Hamburg ig Febr. I666- \pm 20 Nov. 1732 Petersburg. Ottomar ElLliger JR. kreeg te Berlijn het eerste onderricht van zijn vader; na diens dood trok hij naar Amsterdam en werkte bij Michiel van Mus-

*) Opgave van Prof. L. F. de Beaufort. 
scher in I686 bij Gerard de LaIresse, dien hij met groote decoratieve schilderijen hielp.

Gehuwd met Pieternella Leghamers woonde hij in de Amstelkerkstraat te Amsterdam. Zij kregen een zoon Antoni.

Behalve ander werk, maakte hij bloemen- en insectenteekeningen, vooral veel boekillustraties.

Zie: D. S. van Zuiden. De schilders Ottomar Elliger. Vader en zoon. Feestbundel Dr. A. BREdius aangeboden. I8. IV. I9I 5.

In N. A.M. is een titelprent van een manuscript: „De verandering van enighe Rupse en Wurmen". Bij deze titelprent behoort een beschrijving waaruit blijkt dat deze titel bij en in de titelprent behoort, hij is gesigneerd "Otmar Elliger jun. 1725".

Verder behooren bij dit HS. 58 stuks platen van insecten, de meeste met. 2 teekeningen, ongesigneerd.

Van deze teekeningen heeft SEBA gebruik gemaakt voor zijne afbeeldingen v. d. insecten voor dl. IV van zijn Thesaurus, nl. I-3, 32, 49, 50, 52, 53, $59,6 \mathrm{I}-63,65,88,89,92$.

SEBA heeft dit MS. met teekeningen dus in handen gehad, misschien wel in bezit, waaruit dan te verklaren is waarom, op twee plaatsen (op den omslag van een gedeelte tekst en een gedeelte platen) dit werk aan SEBA wordt toegeschreven, en zóó ook opgenomen is onder No. 3555 in Catalogus N. A. M. I88I.

Volgens het art. van H. Engel Tijdschrift voor Entomologie 80, 1937, pag. $\mathrm{XVI}-\mathrm{Xx}$ is dit onjuist.

HAAsbroek. G.

Leefde in de eerste helft der I8e eeuw, hij was een uitmuntend teekenaar van landschappen, land- en watervogels, etc.

N. A. M. bezit een teekening van hem voor Vosmaer's (zie „Auteurs”) Regnum Animale. 1766-I804 van: Giraf of Kameel-Paart van de Caap de Goede Hoop.

HAASTERT, IzaAK, van

I753-I834.

(zie „Handschriften”).

HeEnck. Jabes,

's-Hage 27 Oct. 1752-Nov. I782 Leiden.

Hij teekende vogels op de manier van Aart Schocman, wiens lcerling hij was. Volgens Kram heeft hij fraaie prenten geëtst. Naast dit werk had hij een kunsthandel.

N.A.M. heeft 2 gekleurde waterverf-teekeningen van vogels, waarvan één een Kwartel koning voorstelt 1779.

Hen(G)Stenburg. Herman,

9 Oct. $1667-30$ Oct. 1726.

De eerste beginselen der teekenkunst leerde hij zich zelf en wel door na 
te teekenen. Tot voorbeelden koos hij meestal teekeningen van vogels en landschappen van Pieter Holsteyn. Daar hij dit zoo goed deed, besloten zijn ouders hem in de leer te doen bij Johannes Bronkhorst. Waarschijnlijk ook juist bij hem, opdat BronKhorst hem, behalve het teekenen en schilderen, ook het pasteibakken zou leeren, daar dit hem het voornaamste deel van zijn levensonderhoud opbracht. HENGSTENBURG oefende dit vak tot zijn dood toe uit en liet deze broodwinning toen na aan zijn zoon Antoni, die evenals zijn vader, zich hiernaast, aan de teekenkunst wijdde. Hengstenburg schilderde zijn bloemen, vruchten, torren, hagedissen etc. veel met waterverf op perkament en schijnt het in deze kunst ver gebracht te hebben.

In N. A. M. 3 teekeningen van Insecten.

HeUvel. G. VAN DEN

Volgens v. d. Aa. Biogr. Woordenboek werd hij te Amsterdam geboren en verkreeg in $\mathrm{I} 768$ op de Conf rèriekamer te's-Hage den rang van meester. In 1776 schilderde hij aldaar nog vogels en landschappen.

N. A. M. bezit 3 sepia teekeningen, gemaakt voor Vosmaer's (zie „Auteurs”) Regnum Animale. I766-1804. n.1. Crotalus horridus; Pelamis bicolor +-Platurus fasciatus; Lacerta anguina. (Reptielen). Allen gedateerd 1767 .

Holsteyn. Pieter, de Oude,

Haarlem I582?-

$\mathrm{Hij}$ beoefende het graveeren en etsen op glas. Meestal teekende hij vogels en viervoetige dieren zeer nauwkeurig met mooie kleuren, gelijkend op miniaturen. N. A. M. heeft een ongesigneerde Vogelteckcning (waarschijnlijk v. Holsteyn).

Jeude. 'Theodoor Gerard, van Lidth de

Tiel 8 Aug. I788-23 Dec. I863. Utrecht.

Hij was hoogleeraar te Harderwijk en Utrecht en leeraar aan de Veeartsenijschool te Utrecht, daar stichtte hij een Zoologische tuin (later Tivoli). Hij bracht groote verzamelingen bij elkaar en was een voortreffelijk teekenaar.

Zijn plan was uit te geven: Het Dieren-Rijk of Verzameling van Steendrukplaten, bevattende de Afbeeldingen van verschillende dieren, naar de natuur geteekend, of uit de beste werken overgenomen. Hiervan is nooit meer dan I afl. gedrukt en deze is niet in den handel geweest (bezit N. A. M.). De teekeningen hiervoor heeft v. L. d. J. allen zelf gemaakt en hiervan zijn de meeste, oorspronkelijke, in het bezit van Artis.

Hij was begonnen met het samenstellen van een collectie afbeeldingen uit alle klassen van het dierenrijk. Deze platen, plaatjes en teekeningen maakten zijn beroemden Atras Zoologioue uit. Na zijn dood kwam deze ver- 
zameling in het bezit van R. T. Maitland, die ze bij zijn verzameling voegde en bleef completeeren. Zoodoende kwam deze Iconographia Zoologica in het bezit van N. A. M. (zie artikel Maitland in Bijdr. $t$. d. Dierk. I888).

Ook verscheidene Evertebrata teekende v. L. d. J. en wel wormen voor zijn: Vers intestinam e.a.; veel oorspr. teekeningen zijn hiervan in N. A. M. (zie „Handschriften” en „Auteurs”).

KLAPMUTS. S.

In „de Nederlandsche Vogelen" door Nozeman en Sepp op pag. 92 van Vol. I beschrijft Nozeman een stuk land, gelegen in de Wolle-foppenpolder (d.i. in de buurt van Rotterdam) „waar Reigeren doch nog meer Scholveren (Phalacrocorax carbo) broeden". Hij was over een en ander zoo opgetogen, dat hij hiervan een teekening liet maken. Men ziet hier de broedplaatsen met een enorme hoeveelheid vogels en op den voorgrond een roeibootje waarin o.a. Cornelis Nozeman en S. Klapmuts. Volgens v. d. Aa. Biogr. Woordenb. was KLAPMurs een nederlandsch etser, door KRAMM het eerst genoemd; wanneer hij leefde wordt niet vermeld.

Swierstra schreef $19 \mathrm{Juli}$ I885 in het Handelsblad over deze teekening en zegt dat ' $t$ waarschijnlijk de eenigste is van dit Schollevaarseiland en dat Schlegel deze gebruikte in zijn Vogels van Nederland.

Wat de teekenaar betreft, deze is niet bekend; of zou KLAPMuts hiermee tevens een zelfportret vastgelegd hebben ?

KLINKHAMER.

Het binnenbrengen der kooien met wilde dieren in de Kazerne in 1839 , om later in N. A. M. te worden geplaatst. Potloodteekening.

KuYK. C. vaN,

Teekende voor Vosmaen's Regnum Animale. I766- I804 een sepia teekening van Phacochaerus africanus, die in 't bezit is van N. A. M.

Lyonet. Pieter,

Maastricht 2I Juni I706-'sGravenhage Io Jan. I789.

De voorouders van LYoNeT woonden in Lotharingen doch moesten uit Frankrijk vluchten. Pieter Lyonet had een groote gave voor vreemde talen en ook voor muziek, schilder- graveer- en beeldhouwkunst had hij groote belangstelling. De rechtsgeleerdheid verkoos hij boven het ambt van zijn Vader, die predikant was en zijn zoon gaarne tot dit beroep had opgeleid. Hij studeerde in Leiden, werd advocaat te den Haag toen Secretaris der Cijfers, overzetter van de Fransche taal en patentmeester. Zijn groote liefde ging bij dit alles uit tot de natuurlijke historie en hierbij voornamelijk tot de insecten. Lyonet was van plan de insecten uit de omgeving van den Haag te beschrijven en te teekenen, waarvoor hij reeds vele teekeningen en manuscript had. Dit plan heeft hij echter niet kunnen 
volbrengen (zie bij „Auteurs”, Lyonet, W. DE HaAn). Volgens Alg. Kunst- en Letterbode I86r pag. I94 en Tijdschr. Entom. Ver. IV pag. I4 zijn manuscript en teekeningen in 't bezit geweest van Prof. $C_{L}$. Mulder. $\mathrm{E} r$ is hier sprake van: $16_{3}$ teekeningen met 900 fig. van donsvleugelige insecten en hun metamorphosen. Op de achterkant staan citaten van Albin, Admiral, Reaumur, Merian, Goedaert, Rösel, e.a. Deze I63 teekeningen bezit N. A. M. Waarschijnlijk zijn er meer geweest wat blijkt uit cijfers met potlood bijgeschreven; dit zijn dan misschien de teekeningen, gebruikt door W. DE HAAN voor de Recherches sur l'Anatomie. De aanteekeningen hierbij heeft N.A. M. nooit gehad, waarschijnlijk waren deze indertijd te koop bij Frederik Mur.ler.

Verschillende gegevens en aanwijzingen omtrent deze teekeningen kreeg ik van Dr W. H. van Seters, en volgens hem is dit ,een vondst waardoor tenminste iets van het vele werk van L.yONET is teruggevonden”.

Behalve deze genoemde (zwarte) teekeningen heeft N.A.M. nog een paar andere.

Aвraham Trembly (zie „Auteurs”) schreef zijn bekende werk over Polypen in den tijd, toen hij gouverneur was bij de zonen van Willem Bentinck op Sorgvliet. Lyonet was bevriend met Trembly en teekende de I3 platen der Polypen, hiervoor. De eerste vijf werden gegraveerd door JACOB v. D. Schley en de laatste acht door Lyonet.

Trembley schrijft in zijn voorrede, dat men wel verbaasd zal zijn, dat $L$. de eerste vijf ook niet zelf graveerde, doch in dien tijd verstond hij die kunst nog niet. In 1743 toen die eerste $5 \mathrm{pl}$. gereed waren, was graveeren L. geheel onbekend, hij had 't zelfs nog nooit zien doen. JaN WandelaAR (I690-I759) was echter getroffen door zijn teekenkunst en moedigde hem aan tot het graveeren. Midden Juni begon hij bij WandelaAR lessen te nemen, al dadelijk werden zijn eerste proeven door WANDELAAR meesterwerken genoemd. Lyonet begon aan de platen van Trembly, P1. 6, in Sept. I743 en was met de acht gereed in Febr. I744!

Als men deze platen bekijkt en bedenkt, hoe weinig tijd Lyonet hieraan kon besteden, gezien zijn vele bezigheden, dan moet men eerbied gevoelen voor den man, met deze zoo groote gave, welke niet eens de eenige was, die hij bezat $\mathbf{l}$ ).

Maitland. R. T.

's Hage ?-8 Dec. 1904. 's Hage.

Maitland was verbonden aan N.A. M. I854-I864 als conservator en later weer $1880-1893$. In de tusschenliggende periode was hij eenige jaren directeur van de Haagsche dierentuin.

In den tijd dat hij aan N. A. M. verbonden was zette hij 't werk van vaN

I) In het Prentenkabinet van het Rijks Museum te Amsterdam is (waarschijnlijk) een klein zelfportret van LyoNET. 
Lidt DE Jeude voort (zie aldaar). Maitland heeft zelf hiervoor ook teekeningen gemaakt, o.a. Insecten.

Merian. Maria Sybilla,

Frankfort, I2 Apr. I647 - A'dam, 13 Jan. I7I7.

Haar vader stamde uit Basel, doch trok later naar Duitschland. Hij huwde eerst Maria Magdalena de Brij en voor de ze maal met Johanna Sybilla Heiny; uit dit ze huwelijk werd Maria Sybilla geboren. Haar vader stierf toen ze drie jaar was en haar moeder hertrouwde een jaar later met Jаков MARREL of Moreels, een bloemenschilder uit Holland. Deze stiefvader en Abraham Mignon waren haar meesters. In I665 trouwde Maria Sybilla, Andreas Graff, een schilder uit Neurenberg. Uit dit huwelijk werden twee dochters geboren. Johanna Helena (i668) en Maria Dorothea Henrica (i678). Dit huwelijk, dat waarschijnlijk door de zeer strenge moeder tot stand was gebracht, was niet gelukkig en na veel moeilijkheden gingen ze in I684 uit elkaar. Maria Sybilla trok met haar twee dochters naar Holland, waar zij zich aansloot bij de Labbadisten, die een nederzetting hadden in de buurt van Leeuwarden. Hier kwam zij in aanraking met den Heer van SomerdiJck, die een prachtige verzameling Surinaamsche insecten bezat, welke zij teekende en bestudeerde. Ook de beroemde kabinetten van Witsen, Ruysch en Vincent bezocht zij tot dat doel. Het werk interesseerde haar zóó, dat ze besloot zelf een reis te ondernemen naar Suriname. Men zegt zelfs, dat ze dit deed in opdracht en finantieel gesteund door de Staten Generaal. Met haar dochter Johanna Helena vertrok ze in Juni 1699 naar West Indië.

Ze werkte daar twee jaren, niettegenstaande ziekten en moeilijke omstandigheden, zoodat ze met een heel groot aantal teekeningen van planten, insecten en reptielen naar Holland terug kwam, waarvan er velen zijn verschenen in haar folio-werk: Over de voortteeling en wonderbaarlijke veranderingen der Surinaamsche insecten. De gravures zijn niet door Merian gemaakt, (door J. Mulder en P. Sluyter). In N. A. M. is een zeer mooi met de hand gekleurd exemplaar van dit werk.

Hoe gaarne was Maria Sybilla nog eens naar Suriname gegaan. Ze moest dit plan echter laten varen om gezondheidsredenen. Haar dochter Johanna Helena was echter getrouwd met Joh. Herold, een koopman die handel dreef met Suriname en hierdoor ontving ze nog allerlei wat ze voor haar werk kon gebruiken.

De tweede dochter, Maria Dorothea, die evenals de oudste ook schilderde, had nog meer van haar moeder. Deze was 't dan ook, die het derde deel van het werk afmaakte, door Maria Sybilla begonnen, n.l. Deı Rupsen begin, voedzel en wonderbaare verandering. Behalve deze drie deelen van dit werk, héél mooi gekleurd, bezit N. A. M. de origineele teekeningen met tekst HS. van het derde deel. 
Maria Sybilla's teekeningen zijn meestal geschilderd op een soort zacht, dun melkwit perkament dat bekend is als „carta non nata”, gemaakt uit de huid van ongeboren lammetjes. Twee van deze, prachtige, met nu nog frissche kleuren, geschilderde perkamenten zijn in 't bezit van N. A. M.

Het hollandsch schijnt ze vlug en goed geleerd te hebben, zoodat ze zelfs dichtte in deze taal. Een vierregelig versje, HS. geschreven in een met de hand bijgeschilderd bloemkransje, zooals zij zoo veel maakte, is geplakt in het folio-werk over de Europische insecten:

Aan Juffer Joanna. Koerten-Blok.

Ik heb $u$ penceelen oeft geschonken,

Ioanna wijd en zijds berugt

Door kunst papiere schaaren vrugt

Of 't mee mogt in uw stamboek pronken. zie "Auteurs"

M. S. MeriaAn.

\section{Oort. Pieter van,}

Utrecht ro Oct. I804-25 Sept. I834 Padang.

Van zijn vader, Hendrik van Oort, leerde hij de beginselen van de teekenkunst. Toen hij zich hiermee een beter bestaan wilde verschaffen besloot hij als teekenaar mee te gaan naar Oost-Indië met de Natuurkundige Commissie. In 1824 werd hij door het Rijk daarbij aangesteld en trok met de wetenschappelijke reizigers o.a. naar Timor, Amboina, Nieuw Guinea en Sumatra. Hem schijnt ook nog een wetenschappelijk onderzoek opgedragen te zijn, doch dit bracht hij niet ten einde daar hij reeds in I834 overleed.

Veel werk is niet van hem bekend. N. A. M. bezit 3 aquarellen: 2 insecten en I inktvisch.

Os. George Jacobus Johannes van, Den Haag 20 Nov. 1782--I I (21) Juli I86r Parijs.

Hij was een leerling van zijn vader Jan van Os, die Aart Schouman tot meester had. G. J. J. van Os overtrof, evenals zijn zuster Maria Margaretha en zijn broer Pieter Gerardus, als bloemenschilder zijn vader. Hij teekende de bloemen en planten voor de Flora Batava van Jan Kops. In I 809 behaalde hij een eereprijs bij de Mij. Felix Meritis.

In 1802 vertrok hij naar Sèvres en werkte voor de porceleinfabriek.

Zijn werk werd goed betaald. Soms werkte hij samen met zijn broer PiETER Gerardus.

Jacob van Lennep liet in Sepp Ned. Insecten IV t.o. pag. 48 Sphinx galii door van Os teekenen, uit vreugde dat zijn kleinzoon deze Walstroopij1staart gevonden had.

N. A. M. bezit verscheidene Insectenteekeningen. 
Schepens. Johannes, ?-?

De groote wonderen Gods, beschouwd in het kleine Diertje, de Honigbye. Door veele haarer Leeden, zoo uyt als inwendig met derzelve Koleur en door vergrootglazen zeer naukeurig afgetekend, voor de Oogen te stellen en in het bezonder, het Kunstwerktuyg de Angel,in alle zijne deelen onderzogt door ......

Het is een gecalligraveerd manuscript bestaande uit: een titelplaat (sepiateekening) met Verklaring; een titelblad; r pag. „de Tekenaar aan den Beschouwer"; Io pag. Voorberigt aan den Leeser; 204 pag. Beschrijving van de Afbeeldingen, verdeeld in drie Afdeelingen, groot $8^{\circ}$ gebonden. Op den rug staat: Beschrijvinge der Afbeeldingen van de Honig-Bye door Joh. Schepens.

Hierbij behooren 62 (of 63) zeer nauwkeurige waterverfteekeningen, de meeste van microscopische praeparaten. Bij elk dezer teekeningen behoort een kleine beschrijving in handschrift. $\mathrm{Zij}$ lagen los in een gebonden boek met blanco vellen; op den rug staat: Afbeeldinge van de microscopische ontdekkingen gedaan op en in de Honig-Bye door Johs. Schepens.

Behalve deze teekeningen waren er ook nog:

4 afbeeldingen met beschrijvingen van een vlieg.

I afbeelding v. e. bijen poot.

I afbeelding v. e. vloo.

I afbeelding v. e. zogelembryo.

Allen eveneens waterverfteekeningen.

In het boek ligt een brief aan Schepens van Ploos van Amstel waarin deze hem dankt voor de beschouwing der fraaie teekeningen; de brief is gedateerd 12 Aug. I796. Dit zou kunnen zijn Cornelis Ploos van AmSTEL I4 Jan. 1726 geboren te Weesp, gest. 20 Dec. I798, die een groot bewonderaar was van de beeldende kunsten en zelf een beroemd kunstkabinet bezat.

Verder is mij omtrent dezen Schepens niet bekend. Dr Mac Gillavry toonde tekst en teekeningen op de 66e Wintervergadering v. d. Entomol. Ver. (Dl. 76, pag. xL I933 Tijdschr. v. Entomologie).

\section{Schlegel. Herman,}

Altenburg Io Juni I804-I7 Jan. I884 Leiden.

N. A. M. bezit van Schlegel vele oorspronkelijke teekeningen, om te beginnen : 362 teekeningen (potlood) van de Vogels van Nederland.

Schetsen en teekeningen voor het werk van Schlegel en A. H. Verster v. Wulverhorst. Traité de Fauconnerie I844-I853 waarbij ook enkele van den teekenaar J. WolfF, die na lang zoeken voldeed aan de eischen van Schlegel.

Teekeningen voor: Essai sur la physionomie des Serpens 1837. 
Teekeningen van: Abbildungen neuer oder unvollständig bekannter Amphibien etc. $1837-1844$.

Al de teekeningen en schetsen van: Verhandeling over de vereischten van natuurkundige afbeeldingen. $1849 \mathrm{~d}$. i. de bekroonde prijsvraag van Teylers tweede Genootschap.

Verder nog een menigte gekl. en ongekl. teekeningen en schetsen gediend hebbende voor zijn wetenschappelijk werk.

Schou(w)man. Aart,

Dordrecht 4 Mrt I7IO-5 Juli I792 's-Hage.

Hij was een leerling van AdriaAn van DER BURGH, vestigde zich in den Haag, waar hij o.a. regent der teekenakademie was. Schouman schilderde behalve portretten ook behangsels, wat in dien tijd zeer in de mode was. Hoofdzakelijk maakte hij studies van vogels en andere dieren. Daartoe werkte hij veel op het kìeine Loo bij den Haag en in het vorstelijk Kabinet, beide bezittingen van den Prins van Oranje. Hier maakte hij ook de teekeningen voor Vosmaer's werk (zie „Auteurs”). Regnum Animale dat 1766-I804 in gedeelten verscheen. Van deze uitgave bezit N.A. M. 3 origin. sepiateekeningen en I waterverfteekening.

Voorts van Schouman 6 teekeningen en studies, sepia en waterverf die misschien ook bedoeld waren voor dit werk. Van grooter formaat 7 aquarellen van vogels, waarvan een ,uit Cabinet van den heer I. E. VoET I760". I st. reptiel (Ameira vulgaris).

I st. runderkop (Bos taurus).

I st. zoildzzijn.

I st. marter.

I st. cekhoorn (Sciurus vulgaris).

Als ze gedateerd zijn, is dit tusschen 1743 en 1778 .

Schuba(e)rt. Toers Diesbergen,

Harderwijk 18 Febr. $1805-4$ Oct. 1854 .

$\mathrm{Hij}$ was prosector aan de veeartsenij-school te Utrecht, later ook aan de Hoogeschool en daarbij een uitstekend praeparator en teekenaar. Vele van zijn praeparaten kon hij maken, doordat VROLIK gestorven dieren uit N.A.M. opstuurde naar Utrecht en vaak werden een deel van de geïnjiceerde organen weer teruggestuurd naar Amsterdam, voor de verzameling van Prol. VRolik.

N. A. M. bezit verschillende oorspr. waterverfteekeningen, o.a. I2 stuks van Bombyx mori, behoorende bij een HS. eveneens 7 stuks van Rhipidia, 6 stuks van Pulex en I st. van Acarus.

(Zie ook „Handschriften”).

Sepr. Christuaan,

Goslar begin $18 \mathrm{e}$ eeuw-1775.

Nozeman en Sepp gaven samen uit „Nederlandsche Vogelen”; op 't titel- 
blad staat Christiaan Sepp als teekenaar, doch zijn zoon en kleinzoon hebben er ook aan meegeholpen, daar de uitgave van het werk liep over de jaren $1770-1829$.

In N. A. M. is een aquarel van SEPP: Turdus junco minor (t.o. pag. 98. Vol. II).

(Zie „Auteurs”).

Velten. Jan, \pm I650.

Natuurtooneel bij Blaau Jan. Wonderen der Natuur, die hij selfs in sijn tijt tot Amsterdam gesien heeft, soo Menschen, Dieren, Bloedloose Diertjes, Gevogelte, enz.; heschreven en met de pen na leven geteekendt door Jan Velten. $(1650)$.

Dit foliowerk bestaat uit vele dierteekeningen en andere „Wonderen der Natuur" die Jan Velten ,gezien" heeft, hetzij bij Jan Westerhoff, genaamd JAN BLAAUW of BLAUW JAN.

De figuren zijn met de pen geteekend, sommige gekleurd. Uit bijschriften en jaartallen is allerlei op te maken omtrent dieren die hier te zien zijn geweest in Amsterdam òf bij WesterhofF òf op kermissen.

In het Amsterdamsch Jaarboekje van I889 vindt men een artikel : BLAAUWJaN door D. C. Meyer JR. en in Eigen Haard I888 afl. I3. „Over de vroegere diergaarden en beoefenaars der dierkunde in Nederland" door P. H. Wi'TKamp.

Verheull. Quiryn Maurits Rudolf, Zutfen I I Sept. 1787-io Mei I860 Arnhem.

Verheull was zeeofficier en ging als vrijwilliger naar Oost-Indië, voornamelijk Java en de Molukken waren zijn standplaatsen. In zijn vrijen tijd beoefende hij de entomologie, legde verzamelingen aan en teekende zoowel insecten, planten en conchyliën als landschappen.

O.a. teekende hij de platen voor MiQuel's Illustrationes Piperacearum I844 en werkte mee aan de Nederlandsche Insecten uitg. door J. C. SEPP. Van zijn indische teekeningen bleef niet veel over door den brand op zijn schip de „Evertsen".

In N. A. M. 3 gekl. teekeningen (waarvan I niet gepubliceerd) voor het artikel van A. J. D'Allly in Bijdr. t. d. Dierk. 1I. 2. 1851: Over een steenachtig concrement in het gedarmte $v$. e. paard.

I gekleurde teekening v. Papilio 1855 .

VINNE. VINCENT VAN DE,

Haarlem 1o Juli r684 of '85-i6 Mei I742 Haarlem.

Vincent stamde uit een groote familie van teekenaars en schilders. Zijn grootvader Laurensz Vincent was een leerling van Frans Hals; zijn vader van Berchem. Deze teekende bloemen voor de Haarlemsche bloemkweekers en voor fabriekspatronen. 
VINCENT teekende en etste hoofdzakelijk bloemen en planten.

N. A. M. bezit een vlinder met pop in waterverf 1709 .

Voet. Carel Borchart,

Zwolle. 1670-I745.

$Z$ ijn broeder was burgemeester te $Z$ wolle, die gaarne bloemen, planten en insecten verzamelde. CAREL Borchart kreeg daardoor den lust tot het teekenen en bestudeeren der ,bloedelooze diertjes”. Hij leerde eerst 't goed gebruiken van de verven en makte zulke vorderingen, dat hij op zijn ige jaar aangesteld werd in dienst van den Graaf van Portland, dien hij naar Engeland vergezelde. 's Zomers woonde deze op Zorgvliet bij Den Haag waar Voet ook opdrachten kreeg van STAdHouder Willem III. N. A. M. bezit 12 heel mooie bloemen- en vruchten-aquarellen, zonder datum doch duidelijk gesigneerd.

Zijn zoon was Johannes Fugenius Voet.

Voet. Johannes Eugenius, \pm I $703-28$ Sept. I778. 's-Hage.

Hij was dr. med. Van hem bezit N. A. M.: Insecta Coleoptera in Effigii Originali. Pars II. Tab. XxvI-XL. Ook van Pars I enkele figuren die uitgeknipt zijn en bij samenvoeging weer een geheele bladzijde vormen. De zoo verkregen pagina's komen echter niet altijd overeen met de gedrukte. Dr. D. Mac Gillavry bezit het stel teekeningen compleet (Horn. Schenkling. Index Litt. Entomol. Bd. III, pag. I266, I928) zoodat hieruit blijkt dat VoEt ze waarschijnlijk meer dan eenmaal teekende.

Withoos. Pieter, ?-I695 Amsterdam.

Matrhias Withoos, geboren te Amersfoort i627, een leerling van Jacob van Campen had I dochter en 3 zonen, Johannes, Pieter en Frans die evenals hij de schilderkunst beoefenden en allen, uitgezonderd FRANS, voornamelijk bloemen, planten, vruchten, insecten en kleine dieren tot onderwerp kozen.

N. A. M. bezit een I5-tal waterverfteekeningen van dag-en nachtvlinders en andere insecten van Pieter Withoos die in 1695 , in den bloei zijner jaren, overleed.

\section{HANDSCHRIF'TEN}

in het bezit van N. A. M.

Boddaert. Pieter, i $730-$ I 796.

De volgende brieven, HS. zoowel Lat. als Holl. zijn te zamen gebonden, bezit van N. A. M.; brieven van P. BoddaerT aan:

den Heer Willem van de Meulen, voomaam koopman te Amsterdam, 
etc., behelzende eene nauwkeurige beschrijving en naar het leven vervaardigde afbeelding van den Geharnaschten Klipvisch. (Chaetodonte clupeato) I77I. (Zie ,'Teekeningen");

den Weledelen Hooggeleerden Heere Petrus Luchtmans, Med. Doct. etc., behelzende ...... van de gevleugelde Roch. (Raja alata) I77I. (Zie „Teekeningen") ;

den Weledelen Hooggeleerden Heere Pieter Camper, M. D. v. N. Philosoph. en Medicin Doct. etc., behelzende ... van den langen gemarmerden zuigervisch (Echeneide longissinus marmorato) I772;

den Weledelen Hooggeleerden Heere EduARD SANDIForT, med. doct. etc., behelzende ...... van den Amboinschen Platvisch met eene borstvin. (Pleuronecte monocheiro Amboinensi) I772.

Bij deze brieven, behalve bij de laatste, staat vermeld, dat het beschrijvingen en afbeeldingen zijn van dieren uit de verzameling van Albert Schlosser.

Bole. HeinRich i794-I827.

Brieven HS.

Aan boord der ,Dijkzigt” en te Buitenzorg aan W. DE HaAN.

23 Febr. 1826 en 30 Juni 1826.

$20 \mathrm{Mrt}$ I826.

$20 \mathrm{Juli}$ I826.

6 Dec. I8.26.

Elliger Jun. Ottomar, I666-I732.

(Zie bij „Teekeningen” Elliger).

Groot. B. DE, omstreeks I737.

Parnassus medicinalis illustratus, waarin gehandeld de regno animale, vegetabile et minerale en tegelijk aangetoond de substans en kragt van die dingen, dewelk onder de drie rijken behoren. I737. (P.)

HS. van meer dan I IOO pag. met zeer veel gekleurde penteekeningen, waarbij portret van den schrijver.

HAAN, Wilhem DE, I8OI-I855.

In Jaarboekje N. A. M. I857, pag. 98 staat bij de Geschenken : „van MEvRouw de HAAN- v. Vollenhoven: Een belangrijke verzameling wetenschappelijke aanteekeningen van den Heer W. de Haan". Hieronder waarschijnlijk het posthume werk van $P$. LyONET, met teekeningen.

HaAstert. IzaAk van,

Delft I753-I Mrt 1834. Delft.

Al vroeg openbaarde zich zijn neiging tot de teekenkunst en later kwam daar de dichtkunst bij. Vooral interesseerde hij zich voor de dieren- en plantenwereld, die hij steeds nauwkeurig waarnam en teekende. Hij had teeken- en schilderlessen bij Hiekonymus Lupis, een Venetiaan. v. HaAs- 
TERT legde zich toe in den lateren tijd, op landschappen met dieren gestoffeerd.

In N. A. M. zijn vele teekeningen, meestal in waterverf van insecten, reptielen, vogels, roofdieren en een MS. Natuurlijke Geschiedenis der Spinnen benevens beschrijving en afbeelding van eenige Nederlandsche. z.j. Hierbij behooren 40 oorspr. waterverfteekeningen en I penteekening.

Hasselt. Johan Coenraad van,

HS. 2 brieven aan W. DE HAAN over de natuurlijke historie van Java. Amsterdam, 3 Sept. I8I9 en Anjer I Apr. I823.

Jeude. Theodoor Gerard van Lidth de, I778-i 863 .

N.A. M. bezit een HS. met 14 geteekende pl. voor een Nederlandsche uitgave van zijn:

Recueil de figures des Vers intestinaux, etc. Leide. I829. Hierbij is een Recueil de fig. etc. met gekleurde teekeningen, dat zeer zeldzaam is.

Over de natuurkunde des levenden bewerktuigden dierlijken ligchaams. Zoophysiologia. Een duidelijk HS. gedateerd I3. III. I829.

Anatomia. Dit staat op den rug; geen titelblad. Duidelijk HS. gedateerd 7 Nov. 1829 .

Zoölogisch Museum van Prof. Van Lidth de Jeude te Utrecht. ze Afdeeling. (Zie: „Auteurs” en „Teekeningen”).

Korthals. P. W.

HS. Brieven aan W. DE HAAN.

Krawang en Padang.

I6 Mey 1832 (waarin dood van MackLot).

3० Mey 1833

4 Sept. 1833

2 July 1834

2I Sept. 1834

28 Oct. (?) 1834

Aug. 1835

25 Oct. 1835

22 Febr. 1837.

OORT. P. van,

Brieven HS. aan W. DE HAAN.

Krawang, Residentie Pamanoekan. 28 Mei 1832. Hierin de dood van Macklot.

Schepens. Johannes ? ?

Zie bij ,'Teekeningen”).

Schlegel. Herman. 1804-i 884 .

De bekroonde prijsvraag uitgeschreven door Teylers tweede Genootschap:

Verhandelingen over de vereischten van Natuurkundige Afbeeldingen. 
1849. Hiervan bezit N. A. M. het manuscript met de teekeningen daarbij behoorend en de correspondentie hierover met 'Teylers' Genootschap.

De kleuren, voor zoover zij in aanmerking komen bij het maken van beschrijvingen van voorwerpen uit de natuurlijke geschiedenis, met afb. 2 MSS.

Stoll. Caspar, ?-1795.

N. A.M. bezit een HS. van dezen schrijver: De afbeeldingen der Uitlandsche Dag- en Nagt-Kapellen, voorkomende in de vier deelen van het werk van wijlen den Heere Pieter Cramer. In orde gebragt en gevolgd naar mijne Proeve van eene Systematische rangschikkinge, welke agter het vierde deel van het voornoemde werk is geplaatst ...... door CASPAR STOLL.

Ie deel 1787 , 2e deel 1787 , 3e deel 1787 .

Het supplement op het werk de Uitlandsche kapellen ... door CASPaR STOLL 1787.

Flet bevat geeén afbeeldingen doch alleen beschrijvingen of namen van Vlinders met verwijzingen naar platen. De voorrede is gedateerd I6 May I787. Uytlands ... Capellen ... bijeenvergaard en beschreven door Caspar Stoll. Eerste deel i79I + vervolg.

Dag Capellen etc. Tweede deel I79I + vervolg.

Dag Capellen etc. Derde deel I79I + vervolg.

Nagt Capellen etc. Vierde deel I79I + vervolg.

Het zijn $2 \times 4$ deelen folio, elk met beschrijvingen en namen van en verwijzingen naar, de zich achter in het deel bevindende afb. van Vlinders; dit zijn uitgeknipte exemplaren uit het werk van P. CRAMER.

Het is een manuscript van C. Stoll, wat blijkt uit de opdracht in Dl. I. 9 Jan. I79I.

Zoowel het voorgaande als dit manuscript kloppen niet met de drukken.

Zie bij „Auteurs”).

Schubaert. Toers Diesbergen, I805-1854.

HS. met oorspr. gekl. en ongekl. teekeningen over:

Metamorphose van Rhipidia (met 7 teekeningen).

De ademhalingswerktuigen van Pulex iritans en P. sciurorum (met 6 teek.). Aanteekeningen over de Bombyx movi (met 12 teek.).

Beschrijving van een Acarus-species (met I teek.).

\section{MICROSCOPEN E.A. OUDE INSTRUMENTEN}

In een kleine kast met glazen deuren bevinden zich de oude instrumenten, die een bezit van N. A. M. uitmaken. Aan Dr. W. H. van Seters dankt het Genootschap het, dat deze collectie in 1928 weer op de juiste manier werd samen- 
gesteld en beschreven. Aan deze beschrijvingen met literatuur opgaven, ontleen ik de volgende gegevens.

Enkelvoudig microscoop, tevens prepareer-microscoop van

\section{Mr. Pierre Lyonet (i $706-1789$}

Herkomst: Dit microscoop, gemonteerd op een notenhouten doos met twee schuifladen, dateert van de tweede helft der I8e eeuw en is door Mr. Pierre Lyonet gebruikt als prepareer-loupe en enkelvoudig microscoop bij zijn insectenontledingen.

De verkooping van Lyonet's Naturalienkabinet had I7 April I796 te den Haag plaats. Het microscoop, dat in den veilingscatalogus op pag. 13 onder No. 2 vermeld wordt, werd later doorMej. M. E. A. Oltmans gekocht. Het kwam na haar overlijden in 1838 in het bezit van den Heer Abraham Oltmans, conservator der Conchyliën van het K. Z. G. Natura Artis Magistra.

Dan volgt: Beschrijving; Toebehooren; Gebruik; Verschilpunten; Ontbrekende deelen; Literatuur.

\section{Stam-Microscoop van HeNdRIK HeN (1770-I819).}

Stam-microscoop, gesigneerd: Hendrik Hen, Amsterdam, in mahoniehouten' doos met schuiflade. Omstreeks I800. Hendrik Hen, gedoopt 4 Nov. r770 en overl. I3 Jan. 1819, was physisch instrumentmaker te Amsterdam en woonde aldaar eerst St. Annadwarsstraat en later Kalvẹstraat 35 .

Harting (1850, pg. I6I) roemt hem als een zeer kundig instrumentmaker.

Dit instrument is belangrijk door de uitnemende conservatie, en de aanwezigheid van het verlichtingstoestel van Swaving (1798).

Dan volgt: Beschrijving; Toebehooren; Verlichtingstoestel van Swaving; Literatuur.

Drie-POOT-MicRosCoOP

(Model Scarlet en Culpeper, I8e eeuw).

Beschrijving; Toebehooren; Literatuur.

\section{HOUTEN DRIEPOOT MicRosCoOP}

(type Neurenberg).

Beschrijving ; Literatuur.

$$
\begin{gathered}
\text { ZaK- OF Hand-Microscoor } \\
\text { type Wilson. }
\end{gathered}
$$

Beschrijving; Toebehooren; Literatuur.

Spiegel-Telescoop

van B. Eisma van DER Bildt, Franeker, I8e eeuw. 


\section{REGISTER}

Admiral, Jacob l' I3I, I43, I49

Admiral, Jan l' 143

Aelianus, C. 117

Ahnfelt, A. II5

Ailly, A. J. d' I54

Albertus, Magnus II7

Albinus, B. S. 127, 149

Alcyonius, P. II7

Aldrovandi, U. I 19

Almeloveen, F J. van, I27

Altena, H. L. van 137

Amstel, C. Ploos van 152

Anslijn, N. I35

Aquino, Th. van 117

Aristoteles II7, I I8

Artedi, P. I29

Asper, Hans 118

Ast, B. van der 143

Aubert, H. II7

Bakker, G. I34

Baldaeus, Ph. 124

Bartholomeus, Anglicus I 8

Baster, J. I29, I30

Beaufort, L. F. de I4I

Bellaert, Jacop I 18

Belon, P. I 18

Bennet, J. A. 134

Bentinck, W. I49

Berchem, (C. P.) 154

Berkhey, J. le Francq van 134

Berlin, W. I40

Bik, A. J. I35, 143

Bik, J. F. 135, 143

Bildt, B. Eisma van der 159

Blaauw, Jan 154

Blankaart, S. 124

Bleeker, P. 139, I40, 142

Bleuland I47

Blon, le 143

Bochart, S. 127

Boddaert, P. I30, I32, I45, 155

Boerhaave, H. 123, 128

Boerhaave, J. 128

Bogaert, A. 126

Boie, H. 136, I44, I 55

Bomme, L. 129, I35, 144

Bonaparte, Ch. L. 138

Bontrus 125

Borbonium, L. I 18

Bosman, W. 126

Bout, P. I2I

Braamcamp, G. 145

Brandt, J. C. 133

Breda,J. G. S. van I37
Bredius, A. 146

Bronkhorst, J. van 144, 147

Brugh, A. van der 153

Brugmans, S. J. I34

Bruyn, C. de 125

Bruyn, J. C. de 144

Brij, M. M. de 150

Burman I30

Campen, J. van 155

Camper, A. G. I33, I34

Camper, J. 133

Camper, P. I33, I45, 155

Charante, N. H. van 122

Chemnitz, J. H. I2I

Clusius, C. I 19

Cluyt, D. O. I I9

Cluyt, O. I I9

Colonna, F. II9

Courcelles, P. de I35

Coyett, B. 128

Cramer, P. I32, I58

Cratander, A. I I 7

Culpeper 159

Cuvier, G. I34

Dadelbeek, G. I30, I45

Dapper, 124

Dejean, F. I30

Depreter II5

Dobell, Clifford 122

Draak, R. W. 145

Dusseau, J. L. 135, 138

Eeckhout, A. yan den 125

Egmond, J. A. van I2í

Elliger Jr., O. I27, I45, I46, I56

Elliger Sr., O. 145, 146

Engel, H. 117, 123, 126, 127, 146

Engelmanrı, Th. W. 122

Eyndhoven, A. J. van 132

Fallours, S. i28

Fleck, F. le Sueur 122

Fokke, S. I29

Frémery, N. C. de 134

Fürbringer, M. 140

Gaubius, H. D. 123, 130

Gaza, Th. II7

Gesner, C. 117, 118, I19

Giebel, C. G. II5

Gillavry, D. Mac 152, 155

Giovio, P. I 18

Goedaert, J. 120, 124, 149

Gottorfische Kunst-Kammer 126 
Graaf, N. H. de 132

Graff, A. 150

Grausius, M. 120

Greshoff, M. 125

Gronovius, A. 117,130

Groot, B. de 156

\section{Haag 129}

Haan, W. de I31, I36, I38, I49, 156, 157

Haan-van Vollenhove de 156

Haar, D. ter I/2

Haasbrock, G. 129, 146

Haastert. I. van 122,156

Haaxman, P. J. 122

Halbertsma, H. 122

Hall, H. C. 140

Halma, F. 120

Harlock, W. E. 129

Harting, P. I23, I39

Hasselt, J. C. van 135,157

Heenck, J. 146

Heide, A. de 127

Heiny, J. S. I50

Hen, H. 159

Hen(g)stenburg, H. 146, I47

Henschel, A. G. 121

Herklots, J. A. I32, 140

Herlein, J. D. 126

Herold, J. 150

Heuvel, $G$. van den 129,147

Heyman, J. 126

Hoek, P. P. C. 14I

Hoeven, A. van der 122

Hoeven, J. van der I 37

Hoffmann, C. K. I4I

Hogendorp, van 121

Holsteyn, P. 147

Hoorn, van 125

Hörner, L. 136

Horst, R. 142

Houttuyn, M. 133, I43

Hublard, E. I3I

Hubrecht, A. A. W. 139, I4I

Iconographia Zoologica 148

Jan, Blaauw 154

Janse, G. II5

Jentink, F. A. 140

Jeude, Th. G. van Lidth de 123, 137, 142, 147, I49, I57

Jonge, J. Roman de 121

Jonston 120

Joubert, L. 118

Jovius, P. 118

Kampen, P. N. 142

Kerbert, C. 116, 129, 140

Klapmuts, S. 148

Bijdragen tot de Dierkunde, Afl. 27
Klinkenberg, van 144

Klinkhamer 148

Koerten-Blok, J, I5 I

Kolk, J. L. C. Schroeder van der 137

Kops, J. I5I

Korthals, P. W. 136, I57

Kramm, I46, 148

Kromvelt, $H$. van 122

Kuhl, H. 135

Kuyk, C. van 129,. 148

Laet, J. de 124

Lairesse, G. de 146

Leeuwenhoek, A. van 122, 123

Leghamers, P. 146

Lennep, J. van I5I

Leuckart, R. 140

Lier, J. van 130

Linnaeus, C. 115, 129, 133

Linschoten, J. H. van 124

Lönnberg, E. 129

Luchtmans, P. 156

Lupis, H. 156

Lyonet, P. 116, 131, 138, 148, 149, 156, 158

Macklot, H. C. 136,157

Maitland, R. T. I15, 129, 130, 140, 142, I 48,349

Major, J. D. 119

Man, J. G. de II6, I4I

Manssaci, P. J. II7

Marckgrave, G. van 124, 125

Maris, Jacob I 6

Marrel (Moreel) J. I50

Martens, F. 128

Martinet, J. F. 134

Merian, D. M. H. 123, $150^{\circ}$

Merian, J. H. I50

Merian, M. S. 120, 121, 123, 124, 149, 150, 151

Merula, J. G. IIg

Metzelaar, J. 116

Meulen-Monthaan, H. ter 116

Meulen, W. van de 155

Meyer Jr., D. C. 154

Meyere, J. C. H. de II6

Mignon, A. 150

Miquel 154

Montanus, A. 124

Moor, K. 145

Moubach, A. 128 .

Mulder, Cl. I37, 149

Mulder, J. 150

Muller, Frederik 149

Muller, P. L. Statius 12 I

Muller, W. C. I2I

Musscher, M. van 145 
Nassau, Joan Maurits van 125

Nederlandsche Reizen 126

Neurenberg 159

Nieuhof, H. 125

Nieuhof, J. I25

Nieuwe Stads Herberg 145

Nozeman, C. 133, 148

Olearius, A. 126

Olivier, G. van $\mathbf{I} 34$

Oltmans, A. II6, 159

Oltmans, M. E. A. 159

Oort, E. D. van 142

Oort, P. van I44, 15I, 157

Oranje, Prins van 153

Os, G. J. J. van $15 \mathrm{I}$

Os, J. van 151

Os, Ma. Ma. van I5I

Os, P. G. van 15 I

Outhoven 125

Oudemans, A. C. 120

Pallas, P. S. I30, 13I

Paludanus, L. 127

Pel, H. S. 136

Pfeffel, J. A. 128

Phelsum, M. van I3o

Piso, W. 124, 125

Plinius, C. S. 117

Pollen, F. I 40

Portland, Graaf van 155

Pronk, C. I3I

Pijzel, E. D. 123

Reaumur 149

Reinwardt, C. G. C. I34, I43, I44

Renard, L. 128, 129

Roëll 130

Roggeveen, A. 125

Roggeveen, J. 125

Rondelet, G. II8, II9

Rösel 149

Rouffaer, G. F. I2I

Rumphius, G. E. 120, 121

Ruysch, F. 126, 127, 150

Salviani, I. II9

Sandifort, E. I56

Sandifort, G. 136

Scaligero, J. C. 117

Scarlet 159

Schacht, Oosterdijk 130

Schey,ens, J. 152, 157

Scheuchzer J. J. 127

Schierbeek, A. 123

Schlegel, H. 138, 139, 142, 144, 148, 152, 157
Schley, J. van der 131, 149

Schlosser, J. A. 130, 156

Schou(w)man, A. 129, 146, 151, 153

Schroen, J. T. en L. 118

Schubaert, T. D. 139, 153, 158

Schwartze, Th. v. Duyl- I 16

Seba, A. 127, 146

Sepp, C. 132

Sepp, Chr. 132, 153

Sepp, J. I32

Sepp, J. Chr. I32, I54

Seters, W. H. van 149,158

Sirks, M. J. I35

Slabber, M. 129, I30

Sluiter, C. Ph. I4I

Sluyter, P. 150

Snelleman, J. F. H. I39

Snellen, P. C. T. 132

Somerdyck, van 150

Stell, A. van der 128

Stoll, C. 132, 158

Stracké, Louis .116

Susanna, J. A. I36

Swammerdam. J. 123, 137

Swammerdam, J. Jz. 120

Swierstra 148

Swinderen, Th. van 136,137

Temminck, C. J. 135, 136, 138, 145

Theophrastes 117

Trembley, A. 13I, 149

Triller, D. W. II7

Tyssens, G. 127

Valentyn, F. 12I

Velten, J. I54

Verheul, Q. M. R. 132, 137, 154

Verkolje, J. I22

Verschuiur Jr., W. 116

Veth, H. J. 128, 135, I36

Vincent, L. 120, 121, 126, 127, 150

Vinne, L. van der 154

Vinne, V. van der 154, 155

Vlaming, C. de 128

Voet, C. B. I55

Voet, J. E. 133, I55

Voet, S.(?) E. 153

Vollenhoven, S. C. Snellen van 132

Vosmaer, A. 120, 128, 129, 146, 147, 148, 153

Vosmaer, G. C. J. 142

Vrolik, G. I35

Vrolik, G. W. 135

Vrolik, W. 137, 138

Waarmond 133

Walvischvangst 128 
Wandelaar, J. $\mathrm{I}_{49}$

Weber, Max W. C. 116, 141

Weber-van Bosse, A. II5

Westerhoff, J. I54

Westerman, G. F. II6, I35, 138, I39, I42

Westmaas, E. A. de Roo van $13^{2}$

Willem III 155

Wilson 159

Withoos, F. 155

Withoos, J. 155
Withoos, M. 155

Withoos, P. 155

Witkamp, P. H. 123, 154

Witsen, N. I25, I50

Wolff, J. I52

Worm, O. 126

Wulverhorst, A. H. Verster vân 152

Zorgdrager, C. G. 128

Zuiden, D. S. van $14^{6}$ 

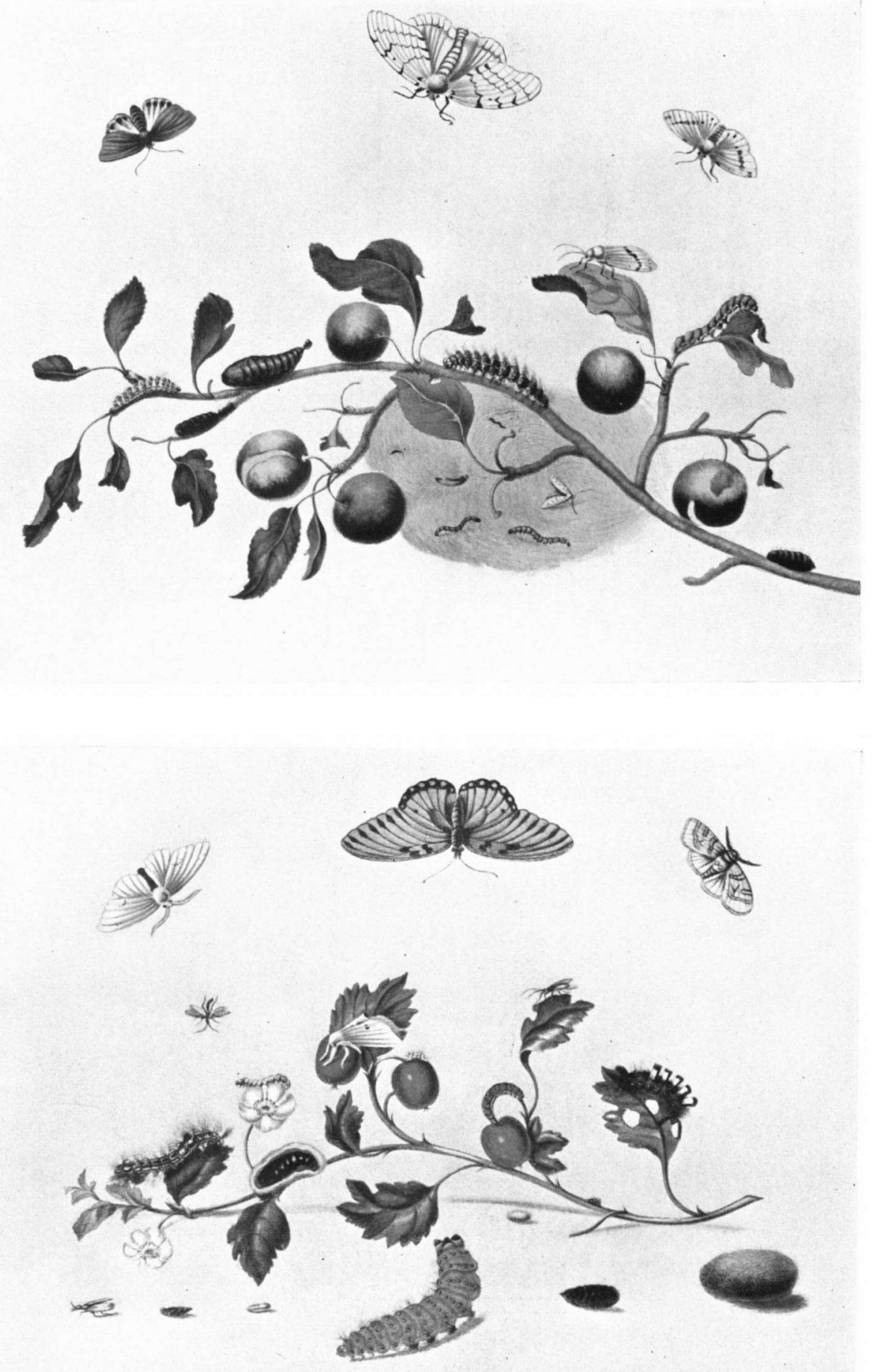

MARIA SYBIILLA MERIAN

1647-1717

Alquarcllen of perkament, in besit van "Natura Artis Margistra" Brill.come4/25/2023 11:37:15PM 



CAREL BORCHART VOET

$$
1670-1745
$$

Aquarellen in bezit van "Natura Artis Magistra" 